LA--10261-MS

DE86 005880

UC-70B

issued: November 1985

\title{
Consolidation and Shear Failure Leading to Subsidence and Settlement \\ Part I
}

W. V. Abeele

\begin{abstract}
DISCLAIMER
This report was prepared as an account of work sponisored by an agency of the United States Government. Neither the United States Government nor any agency thereof, nor any of their employees, makes any warranty, express or implied, or assumes any legal liability or responsibility ior the accuracy, completeness, or usefulness of any information, apparatus, product, or process disclojed, or represents that its use would not infringe privately owned rights. Reference herein to any specific commercial product, process, or service by trade name, trademark, manufacturer, or otherwise does not necessarily constitute or imply its endorsement, recemmendation, or favoring by the United States Government or any agency thereof. The views and opinions of authors expressed herein do not necessarily state or reflect those of the United States Government or any agency thereof.
\end{abstract}
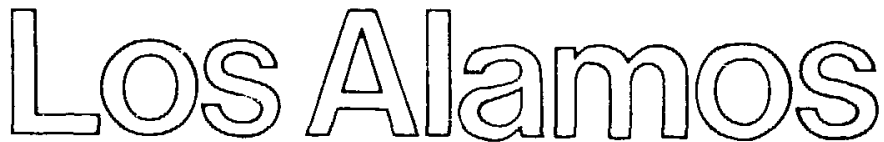

Los Alamos National Laboratory Los Alamos,New Mexico 87545 


\title{
CONSOLIDATION AND SHEAR FAILURE LEADING TO SUBSIDENCE AND SETTLEMENT
}

Part I

by

W. V. Abeele

\begin{abstract}
Subsidence and settlement are phenomena that are much more destructive than generally thought. In shallow land burials they may lead to cracking of the overburden and eventual exposure and escape of waste material. The primary causes are consolidation and cave-ins. Laboratory studies performed it Los Alamos permit us to predict settlement caused by consolidation or natural compaction of the crushed tuff overburden. We have also investigated the shear failure characteristics of crushed tuff that may lead to subsidence. Examples of expected settlement and subsidence are calculated based on the known geotechnical characteristics of crushed tuff. The same thing is done for bentonite/tuff mixes because some field experiments were performed using this additive (bentonite) to reduce the hydraulic conductivity of the crushed tuff. Remedial actions, i.e., means to limit the amount of settlement, are discussed. Finally, we briefly comment on our current field experiment, which studies the influence of subsidence on layered systems in general and on biobarriers in particular.
\end{abstract}

\section{INTRODUCTION}

\section{A. Evidence of Occurrence}

1. General. Engineering structures may cause foundation failures in one of two ways: excessive settlement or shear failure of the supporting soil. These iailures are caused by (1) unexpected increase or decrease in soil moisture content, (2) compaction under unforeseen pressures, (3) soil heave caused by frost action and settlement caused by thaw, and (4) creep and slides resulting from shear failure (Jumikis 1968). The engineering structures involved may include whole cities (Mexico City), bullding complexes, or parts of buildings. Partial building subsidence is primarily caused by urieven soii settlement. The best known example of this is the Leaning Tower of Pisa, which is famous only because it has not fallen down in eight centuries despite its still settling foundations. Total subsidence in Mexico City has passed the $10 \mathrm{~m}$ mark since the beginning of this century but uneven settlement or subsidence is much more damaging than total subsidence and results in disastrous ruptures of the sewer system and pipelines-cracking, tilting, and subsidence of monuments and buildings, old and moder „.. Such soil settlement in Mexico City can be studied as large-scale consolidation tests.

Vibrations can also have a densification effect on soils and lead to subsequent settlement. The effects can be severe when the vibration frequency matches the soil's natural frequency. Soils often fail and settle disastrously as a result of earthquakes. Devastating landslides are often one of the results of such occurrences. Most earthquake accelerations, however, are too small to cause densification and only large earthquakes will cause subsidence of the upper soil layer, which may 
amount to more than $1 \mathrm{~m}$ at large accelerations as occurred in Valdivia, Chile in 1960 (Lambe and Whitman 1979). Natural or anthropogenic modification of the landscape, such as slopes or modification of supporting medium in landfills, may also be subject to failure. Differential settlements are usually structurally the most critical.

Of the three phases possibly present in a soil, only the solid phase controls the resistance to compression and shear. Water, present in a moist soil, is highly incompressible but, as a liquid, is, by definition, not capable of resisting shear lsads. Air, present in unsaturated soils, will not support compression or shear loads.

In a saturated soil, compression will be primarily caused by expulsion of water out of the soil voids. Under the influence of an externally applied load, the expulsion of water from the voids is highly dependent on the permeability of the medium. The extremely low permeability in the case of clay leads to a slow void contraction. The compression of saturated, low permeability layers under a static pressure is known as consolidation. The consolidation rate depends on the compressibility of the soil (rate of decrease in volume with stress) and soil permeability, which, in turn, is dependent on the viscosity of the liquid (viscosity of water at $35^{\circ} \mathrm{C}$ is half that at $5^{\circ} \mathrm{C}$ ). An increase in temperature increases the consolidation rate but cloes not affect rotal amount of consolidation (Head 1982).

The oedometer test maintains a constant stress until settlement is virtually complete and no evidence of neutral stress or pore pressure remains (Fig. 1). Initially, the stress is converted into increased pore pressure. As water is expelled out of the soil voids, the pore pressure gradually drops to zero. The results are read as a plot of void ratio vs time for a given total stress (pore stress + effective stress).

Failure to drain the pores will result in low shear resistance. The ability to resist shear loads is solely dependent on the mechanical interaction of the solid particles in the soil matrix. The presence of excess water reduces the effective stress responsible for the friction between solids.

Quantitative studies involving the physical and mechanical properties of soils and having direct application on the design or the construction of waste disposal facilities include hydraulic conductivity, consolidation, and shear strength. Long-term soil consolidation and shear failure will result in subsidence.

Several reports dealing with the hydraulic conductivity of crushed and solid Bandelier tuff, as well as adjacent soils, ha been published on the subject (Abeele 1979. Abeele et al. 1981, Abrahams 1963, Abrahams et al. 1961. Purtymun and Koopman 1965). Consolidation and shear strength are discussed below.

2. Shallow Land Burial. Uneven settlement or differential settlement is far more damaging to a pit overburden than is total settlement. It will lead to cracking of the overburden and eventual exposure and escape of wastc material. Differential or partial settlement is very often described as subsidence, although I found the terms are often used interchangeably. The nonhomogeneity of the buried waste and containers is the major cause for differential settlement. This nonhomogeneity is also the cause of temporary arching and sudden collapse or subsidence. It is also the reason that differential settlement is so much more difficult to estimate.

Exposure of waste materials is studied in our field experiment. This study concerns the integrity of a biobarrier when collapse, subsidence, or disruption of a soil layer (e.g., a biobarrier) occurs.

\section{B. Causes}

The magnitude of soil settlements deper.is on the compressibility of the scil, moisture and iemperature fluctuations in the soil, and the stresses applied upon it. Several broad causes for soil settlement are recognized:

\section{Consolidation.}

2. Lateral and upward expulsion of cohesionless or saturated soil masses. 
INITIAL

WATER SURFACE
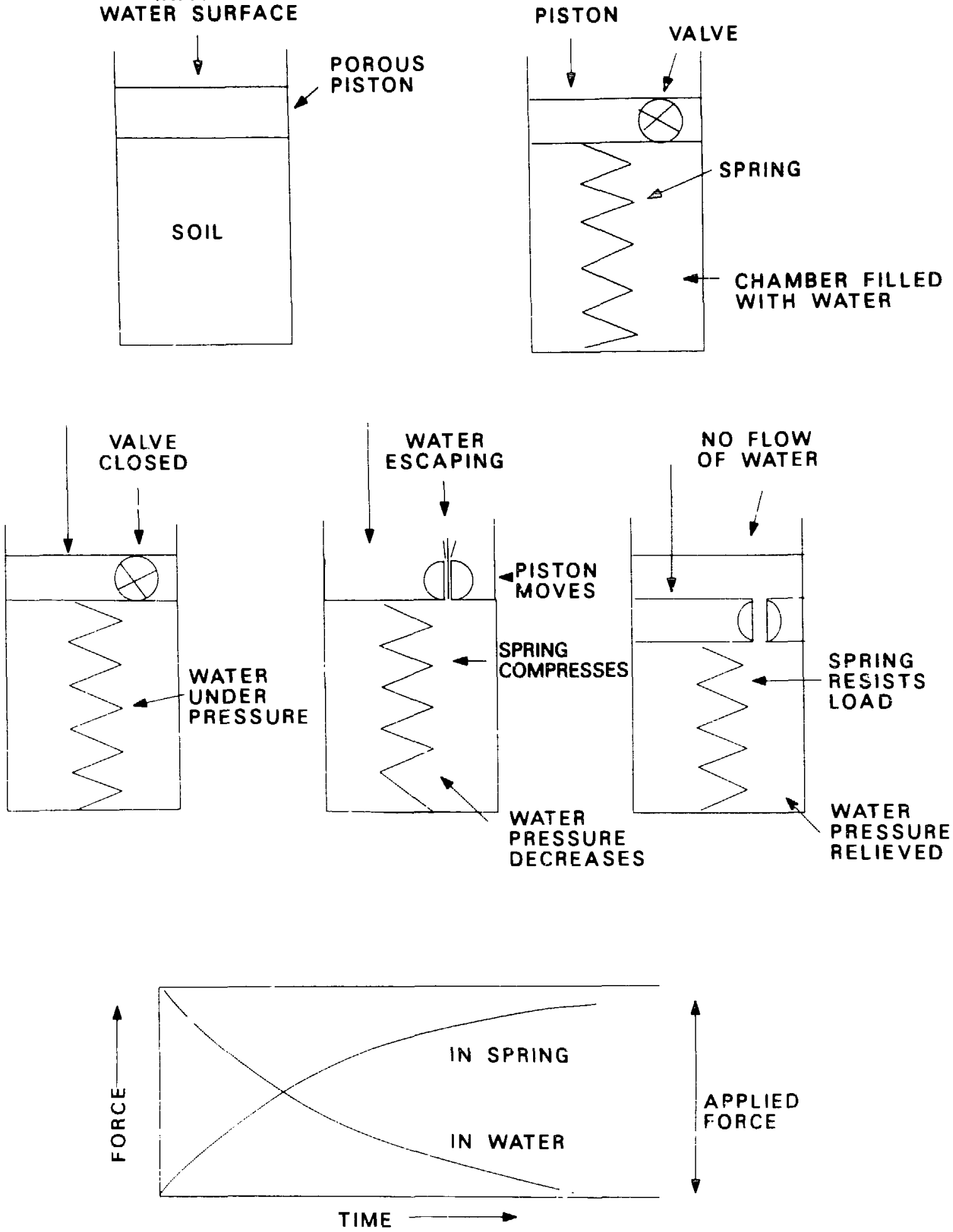

Fig. 1. Hydromechanical analogy for consolidation. 
3. Cave-ins resulting from

(a) Unbraced excavations such as shallow land burial pits either before or after backfilling. This is caused by exceeding the shear strength of the slope.

(b) Rotting or degradation of the waste products serving as braces and support for the overburden or backfill.

(c) Slumping of the overburden, which is caused by movement of soil particles into existing interstices between waste containers.

(d) Decreased soil shear strength through wetting.

(e) Large-scale dewatering.

4. Inadequate soil compaction.

Table I, borrowed from Sowers (1979) indicates the principal causes of settlement; Table Il indicaies the pressures at which a typıcal material will fail.

\section{Mechanisms}

Settlement means some form of densification. Minimum density is obtained by measuring oven-dried soil, which has been poured into a container of known volume. Maximum density is obtained by vibrating that container according to (not entirely standardized) specifications. In general, the smaller the particle size distribution, the lower the density. The relative density of a granular medium or soil is defined as

$\mathrm{D}_{\mathrm{r}}=\frac{\mathrm{e}_{\max }-\mathrm{e}}{\mathrm{e}_{\max }-\mathrm{e}_{\min }} \times 100 \%$

where $=$ void ratio

The density of granular soils (Table III) is characterized according to Lambe and Whitman (1979). Several interdepender.t mechanisms contribute to the densification of granular soils:

1. Compression of air and water in the voids.

2. Squeezing of air and water out of voids.

3. Permanent deformation caused by crushing of particles.

4. Elastic deformation caused by bending of particles.

5. Rearrangement of particles caused by sliding and rolling of particles relative to one another.

The property that influences deformation and consequent settlement to the greatest extent is the modulus of elasticity or the stress/strain modulus, E. The bearing capacity of a granular soil depends to a high degic: on the internal friction angle or angle of repose (see Sec. II.B.) and on the relative density of the granular soil in question.

\section{STUDIES AT LOS ALAMOS}

\section{A. Consolidaticn}

Loading a soil with a manmade fill will cause deformation. The resulting total yertical surface deformation or displacement is described as settlement. Also, a lowering of the water table will cause an increase in the effective stress, $\sigma_{\mathrm{eff}}$, and cause $r$ ttlements. The total settlement, $\Delta \mathrm{H}$, has three components (Holtz 1981): 
TABLE I

\section{CAUSES OF SETTLEMENT}

Cause
Form of Mechanism

Amount of Settlement

Distortion (change in shape of soil
mass)

\begin{tabular}{l|l|}
\hline & mass) \\
\hline & $\begin{array}{l}\text { Consolidation: Initial } \\
\text { Change in void } \\
\text { stress }\end{array}$ \\
\hline Environmental load & Shrinkage (due to drying) \\
\hline
\end{tabular}
(but may be aggravated by load; often environment related, but not dependent)
Consolidation (due to water table lowering)

Reorientation of grains-shock and vibration

Structural collapse-loss of bonding (saturation thawing, etc.)

Raveling-erosion into openings, cavities

\begin{tabular}{|l|}
\hline Biochemical decay \\
\hline Chemical attack \\
\hline $\begin{array}{l}\text { Mass collapse-collapse of sewer, } \\
\text { mine, cave }\end{array}$ \\
\hline $\begin{array}{l}\text { Mass distortion-shear-creep or } \\
\text { landslide in slope }\end{array}$ \\
\hline $\begin{array}{l}\text { Expansion-frost, clay expansion, } \\
\text { chemical attack (resembles } \\
\text { settlement) }\end{array}$ \\
\hline
\end{tabular}

Rate of Settlement

\begin{tabular}{|c|c|}
\hline $\begin{array}{l}\text { Compute by elastic theory (partly } \\
\text { included in consolidation) }\end{array}$ & Instantaneous \\
\hline Stress-void ratio curve, time curve & Rapid \\
\hline Stress-void ratio curve & Compute form Terzaghi theory \\
\hline Compute from log time-settlement & Compute from log time-settlement \\
\hline $\begin{array}{l}\text { Estimate from stress-void ratio or } \\
\text { moisture- } v \text { id ratio and moisture } \\
\text { loss limit surinkage limit }\end{array}$ & $\begin{array}{l}\text { Equal to rate of drying. Seldom can } \\
\text { be estimated }\end{array}$ \\
\hline $\begin{array}{l}\text { Compute from stress-void ratio and } \\
\text { stress change }\end{array}$ & Compute from Terzaghi theory \\
\hline $\begin{array}{l}\text { Estimate limit from relative density } \\
\text { (up to } 60-70 \% \text { ) }\end{array}$ & $\begin{array}{l}\text { Erratic, depends on shock, relative } \\
\text { density }\end{array}$ \\
\hline $\begin{array}{l}\text { Estimate susceptibility and possibly } \\
\text { limiting amount }\end{array}$ & $\begin{array}{l}\text { Begins with environmental change, } \\
\text { rate erratic }\end{array}$ \\
\hline $\begin{array}{l}\text { Estimate susceptibility but not } \\
\text { amount }\end{array}$ & $\begin{array}{l}\text { Erratic, gradual or catastrophic, } \\
\text { often increasing }\end{array}$ \\
\hline Estimate susceptibility, possible limits & Erratic, often decreases with time \\
\hline Estimate susceptibility & Erratic \\
\hline Estimate susceptibility & Likely to be catastrophic \\
\hline $\begin{array}{l}\text { Compute susceptioility from stability } \\
\text { analysis }\end{array}$ & Erratic, catastrophic to slow \\
\hline $\begin{array}{l}\text { Estimate susceptibility sometimes } \\
\text { limiting amount }\end{array}$ & Erratic, increases with wet weather \\
\hline
\end{tabular}

Reprinted with permission of Macmillan Publishing Company from Soil Mechanics and Foundations: Geotechnical Engune'ring by G. F. Sowers, (O) 1979 by Macmillan. 
FAILURE PRESSURES FOR TYPICAL MATERIALS

\begin{tabular}{|c|c|}
\hline Material & $\begin{array}{c}\text { Pressure } \\
\text { (kPa) }\end{array}$ \\
\hline Soft Clay & 45 \\
\hline Submerged Loose Sand & 60 \\
\hline Dry Loose Sand & 100 \\
\hline Stiff Clay & 175 \\
\hline Submerged Dense Sand & 240 \\
\hline Hard Clay & 400 \\
\hline Dry Dense Sand & 500 \\
\hline Weathered Rock & 500 \\
\hline Hard Rock & 10000 \\
\hline
\end{tabular}

DENSITY OF GRANULAR SOILS

\begin{tabular}{|c|c|}
\hline$D_{r}(\%)$ & Description \\
\hline $0-15$ & Very Loose \\
\hline $15-35$ & Loose \\
\hline $35-65$ & Medium \\
\hline $65-85$ & Dense \\
\hline $85-100$ & Very Dense \\
\hline
\end{tabular}

$\Delta \mathrm{H}_{1}=$ immediate settlement or distortion.

$\Delta \mathrm{H}_{2}=$ time-dependent settlement or consolidation.

$\Delta \mathrm{H}_{3}=$ secondary time-dependent settlement.

The distortion component can be estimated using the elastic theory where, according to Hooke's law,

$\Delta H=\frac{P H}{E A}$.

with

$\mathrm{E}=$ elasticity modulus in $\mathrm{Pa}$.

$\mathrm{P}=$ load in $\mathrm{N}$,

$\mathrm{H}=$ thickness of soil layer in $\mathrm{m}$.

$A=$ area of soil under stress.

The elasticity modulus is determined by the slope of the initial stress/strain curves. This can be done by taking the initial slope of the stress/strain curve, called the tangent modulus or, because the stress/strain curves are not entirely linear, by taking the slope of the straight line from the origin to a certain stress, which is called the secant modulus (Holtz and Kovacs 1981).

When additional stress is applied to the saturated soil, the solid structure will not immediately support it because water wi:! nrevent compression. Pore precsure supports the applied load. As the water is forced out, the soil compres.s? and the solid structı : assumes more and more of the load until the neutral stress becomes zero and the solid particles su pport the total load or effective stress. The neutral stress can be read by a piezometer. Since pore water pressure measurements are not made in the oedometer, the degree of consolidation, $U$, is calculated directly from the change in height, $H$, of the sample, with $U=0 \%$ at the start of the consolidation and $U=100 \%$ at its completion. The change in void ratio

$\Delta \mathrm{e}=\left(1+\mathrm{e}_{\mathrm{o}}\right) \Delta \mathrm{H} / \mathrm{H}_{\mathrm{o}}$

The time required to reach any percentage of consolidation for any thickness of a particular soil layer can be evaluated from the consolidation curve obtained in the laboratory. The time for any degree of consolidation will be a function of the square of the thickness of a particular soil layer and 
its permeability at that particular consolidation pressure, so that rate and amount of settlement of a structure can be calculated. This would enable one to estimate whether settlements will be substantially completed during construction or how long the settlements will last after completion. Means for accelerating the consolidation, such as sand drains or wicks, may be considered.

After equilibrium is reached and the transfer from neutral to effective stress is complete, the test proceeds by addition of a new load increment and by allowing settlement to occur until equilibrium is reached under the new total stress, indicating the new consolidation is complete. For adequate computations of the coefficient of consolidation, $C_{v}$, standard load increments of $\Delta \sigma / \sigma=$ 1 must be used. This value, $C_{v}$, varies for each stress increment and is, therefore, calculated every time a load increment is applied. A total final stress of $1 \mathrm{MPa}$ was applied. The time rate for each settlement measurement during each load increment test was set at $\Delta t / t=1$. It is important to remember that the rate of settiement is primarily a function of the compressibility and permeability of the medium. The coefficient of volume compressibility $\mathrm{m}_{\mathrm{v}}=\mathrm{d} \varepsilon / \mathrm{d} \sigma$ with $\varepsilon=\Delta \mathrm{H} / \mathrm{H}$ the relative strain or compressibility. It is noteworthy that $m_{v}$ is the reciprocal of the modulus of elasticity, compression, or constraint. If the void ratio at equilibrium is plotted against applied stress, the slope of the curve is termed the coefficient of compressibility

$\mathrm{a}_{\mathrm{v}}=\mathrm{de} / \mathrm{d} \sigma=\mathrm{m},(1+\mathrm{e})$.

with $e$ the void ratio. The compression modulus $M_{v}=1 / m_{v}$ also gives an indication of soil compressibility. The higher the $\mathrm{M}_{\mathrm{v}}$ value, the less compressible the soil.

The compression characteristics of overconsolidated soil are demonstrated by the rebound (also known as uiloading. decompression, swelling) and recompression curve. If recompression surpasses I MPa (the previous maximum stress), a straight line parallel to the already existing one will be obtained. The recompression curve indicates a clay that is overconsolidated and much less compressible than normally consolidated clays. The rebound is characteristic of the elastic deformation of the soil, whereas the difference between original and rebound height is indicative of the plastic deformation of the soil. Elastic deformation is reversible and is primarily caused by bending and distortion of the solid matrix, whereas reorientation and fracture of the solio particles account for plastic deformation.

Recompression curves typicaily occur in preconsolidated soils, which are soils once subjected to a stress exceeding the present overburden pressure. Removal of that overburden by erosion, melting, lowering of the water table, or excavation leaves a soil preconsolidated. Most undisturbed soils are preconsolidated to some extent. This fact is extremely important in foundation engineering because such a soil will not settle appreciably until the stress imposed exceeds the preconsolidated stress (Sowers 1979). An unconsolidated soil with a low $C_{v}$ can be preloaded with fill if normal consolidation is expected to last until after completion of the structure.

The coefficient of consolidation increases with increased permeability and decreased compressibility and is also inversely proportional to the specific weight of the diffusing fluid. Consequently,

$\mathrm{k}=\mathrm{C}_{v} \lambda_{\mathrm{w}} \mathrm{m}$.

1. Hackroy Series. The soil studied is a mixture of a typical profile of a Hackroy series, consisting of a loam, clay loam, and clay obtained from the Experimental Engineering Waste Burial Facility in Los Alamos, New Mexico.

The specimen dimensions were $100 \mathrm{~mm} \times 100 \mathrm{~mm} \times 25.5 \mathrm{mim}$.

Moisture ratio by mass: 0.348 .

Mass of dry soil: $341 \mathrm{~g}$.

Particle density: $2.50 \mathrm{Mg} \mathrm{m}^{-3}$ (measured).

Initial void ratio: $0.348 \times 2.5=0.87$.

Porosity: $0.87 / 1.87=0.465$.

Bulk density (dry): $2.5 / 1.87=1.337 \mathrm{Mg} \mathrm{m}^{-3}$. 
Moiscure ratio by volume: $0.348 \times 1.337=0.465$.

Saturated unit weight: $(2.5+0.87) / 1.87=1.802 \mathrm{Mg} \mathrm{m}^{-3}$.

Volume: $341 / 1.337=255 \mathrm{~cm}^{3}$.

Height of sample: $25.5 \mathrm{~mm}$.

Liquid limit: $30 \% \rightarrow C_{r}=0.14$ (calculated compression index).

Plasticity index: 5-10.

Both $m_{v}$ and $a_{v}$ and the computed hydraulic conductivity are seen to decrease with increasing stress (Table IV). The stress vs void ratio graph with log stress as the abscissa and void ratio as ordinate approximates a straight line. The compression index, $C_{c}$, is the slope of the straight line, where

$\Delta \mathrm{e}=-\mathrm{C}_{\mathrm{c}} \log \sigma / \sigma_{\mathrm{o}}$

The index. $C_{c}$, is equal to 0.14345 above $60 \mathrm{kPa}$, where the line is straight (the higher $\mathrm{C}_{\mathrm{c}}$, the higher the compressiblity of the material). The consolidation characteristics of a normally consolidated soil are depicted in the straight-line portion of the curve in Fig. 2. The swelling index is equal to 0.01826 or $13 \%$ of the compression index.

TABLE IV

$C_{v}, m_{v}, A N D k$ AS A FUNCTION OF STRESS FOR HACKROY SERIES

\begin{tabular}{|c|c|c|c|c|c|}
\hline$\sigma(k P a)$ & $C_{v}\left(10^{-6} m^{2} s^{-1}\right)$ & $\mathrm{m}_{v}\left(10^{-7} \mathrm{~Pa}^{-1}\right)$ & $\mathbf{M}_{v}(\mathbf{M P a})$ & $\mathbf{a}_{v}\left(10^{-7} \mathbf{P a}^{-1}\right)$ & $\mathrm{k}\left(10^{-9} \mathrm{~ms}^{-1}\right)$ \\
\hline 60 & 1.40 & 7.63 & 1.31 & 13.72 & 10.70 \\
\hline 120 & 1.33 & 3.37 & 2.97 & 5.89 & 4.49 \\
\hline 250 & 1.47 & 1.87 & 5.35 & 3.19 & 2.75 \\
\hline 500 & 1.28 & 1.27 & 7.87 & 2.11 & 1.62 \\
\hline 1000 & 1.26 & 1.27 & 7.87 & 2.05 & 1.60 \\
\hline
\end{tabular}

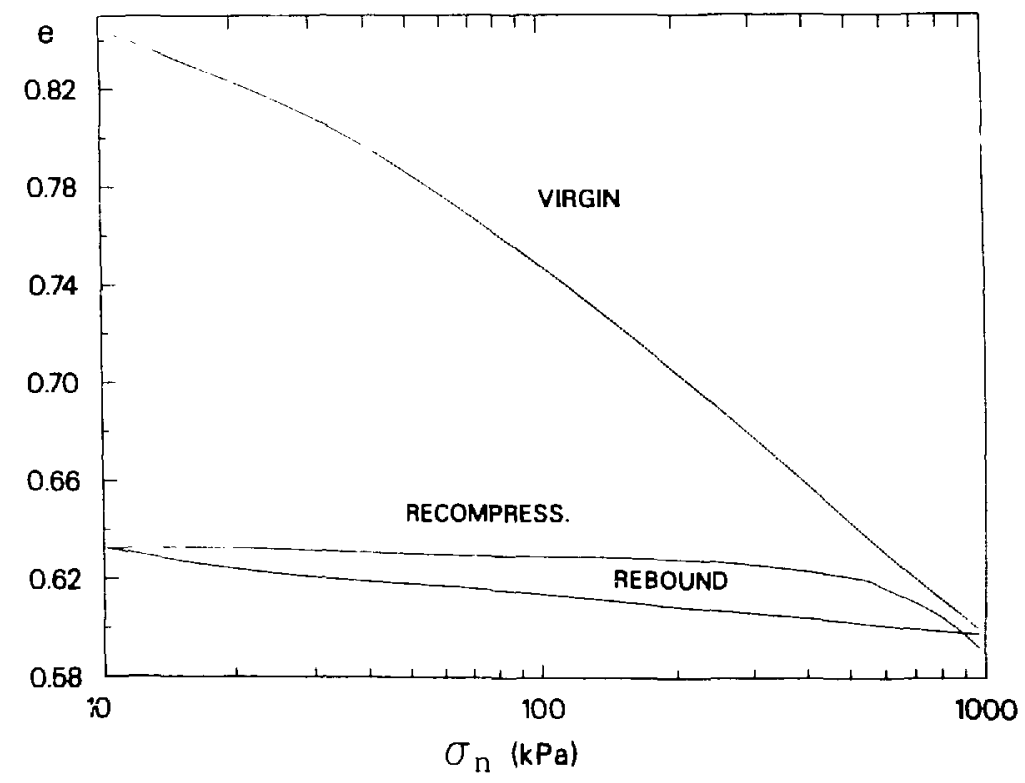

Fig. 2. Virgin, rebound, and recompression curves for the Hackroy series soil. 
The recompression curve follows a path more or less parallel to the rebound curve until the preconsolidation stress of $1 \mathrm{MPa}$ is reached. Beyond the preconsolidation point, a fast acceleration in void ratio decrease takes place, and the recompression curve merges with the virgin curve. The virgin, rebound, and recompression values at specific stresses are indicated in Table $\mathrm{V}$ and plotted in Fig. 2. It is clear from the graph that most of the deformation is plastic. This is to be expected considering the magnitudes of the contact pressures involved and the modulus of elasticity of soil grains, which is on the order of $20 \mathrm{GPa}$. Through regression analysis, we are able to determine that the best fit existing between hydraulic conductivity, $\mathrm{k}$, as dependent variable and void ratio, E, as independent variable is $\mathrm{k}=2 \cdot 10^{-12} \mathrm{e}^{10.84 \mathrm{E}}$ with $\mathrm{k}$ in $\mathrm{ms}^{-1}$. The coefficient of correlation is better than 0.94 . This enables us to estimate the hydraulic conductivity for a nonconsolidated sample ( $E$ $=0.87$ ) as being equal to $2.5 \cdot 10^{-8} \mathrm{~ms}^{-1}$ or about 60 times smaller than that of crushed tuff.

2. Crushed Bandelier Tuff. Crushed Bandelier tuff has a grain size distribution close to that of a sandy silt.

The specimen dimensions were $100 \mathrm{~mm} \times 100 \mathrm{~mm} \times 26 \mathrm{~mm}$.

Mass of dry soil: $365 \mathrm{~g}$.

Moisture ratio by mass: 0.323 .

Particle density: $2.56 \mathrm{Mg} \mathrm{m}^{-3}$ (measured).

Initial void ratio: $0.323 \times 2.56=0.83$.

Porosity: $0.83 / 1.83=0.453$.

Dry bulk density: $2.56 / 1.83=1.40 \mathrm{Mg} \mathrm{m}^{-3}$.

Moisture ratio by volume: $0.323 \times 1.40=0.45$.

Saturated unit weight: $(2.56+0.83) / 1.83=1.85 \mathrm{Mg} \mathrm{m}^{-3}$.

Volume: $365 / 1.40=260 \mathrm{~cm}^{3}$.

Height of sample: $26 \mathrm{~mm}$.

TABLE V

\section{$\mathrm{H}, \triangle \mathrm{e}, \mathrm{e}, \triangle \mathrm{H} / \mathrm{H}$ AS A FUNCTION OF STRESS FOR THE VIRGIN, REBOUND, AND RECOMPRESSION CURVES FOR HACKROY SERIES}

$\begin{array}{rrrrrr}\sigma(\mathbf{k P a}) & \mathrm{H}(\mathrm{mm}) & \Delta \mathrm{e} & \mathrm{e} & \Delta \mathrm{H} / \mathrm{H} \\ 10 & -0.350 & -0.02567 & 0.84433 & -0.01373 \\ 20 & -0.650 & -0.04767 & 0.82233 & -0.02549 \\ 60 & -1.428 & -0.10472 & 0.76528 & -0.05600 \\ 120 & -1.944 & -0.14256 & 0.72744 & -0.07624 \\ 250 & -2.564 & -0.18803 & 0.68197 & -0.10055 \\ 500 & -3.132 & -0.22968 & 0.64032 & -0.12282 \\ 1000 & -3.818 & -0.27999 & 0.59001 & -0.14973 \\ 600 & -3.756 & -0.27544 & 0.59456 & -0.14729 \\ 400 & -3.710 & -0.27207 & 0.59793 & -0.14549 \\ 200 & -3.642 & -0.26708 & 0.60292 & -0.14282 \\ 100 & -3.568 & -0.26165 & 0.60835 & -0.13992 \\ 10 & -3.320 & -0.24347 & 0.62653 & -0.13020 \\ 100 & -3.358 & -0.24625 & 0.62375 & -0.13169 \\ 200 & -3.381 & -0.24792 & 0.62208 & -0.13259 \\ 400 & -3.438 & -0.25214 & 0.61786 & -0.13482 \\ 600 & -3.546 & -0.26006 & 0.60994 & -0.13906 \\ 1000 & -3.928 & -0.28805 & 0.58195 & -0.15404\end{array}$


During consolidation, the data yielded void ratio-log time curves concave upward from the start, indicating extremely fast consolidation. The point, $\mathfrak{t}_{50}$, indicating the time at which $50 \%$ of the consolidation is complete, was always passed before the first measurement could be taken (at about $0.05 \mathrm{~min}$ ). For our specimen of $26-\mathrm{mm}$ thickness, $C_{v}$ will then be at least $346 \mathrm{~m}^{2} /$ year or $1.1 \cdot 10^{-5} \mathrm{~m}^{2} \mathrm{~s}^{-1}$. The hydraulic conductivity, as well as both $\mathrm{m}_{\mathrm{v}}$ and $\mathrm{a}_{\mathrm{v}}$, on the other hand, decreases with increasing stress (Table VI). The compression index, $C_{c}$, is equal to 0.14635 above $60 \mathrm{kPa}$. The void ratio-stress curve is slightly convex upward. The swelling index, $S_{c}$, equal to 0.01567 , is smaller than that of the Hackroy series and is $11 \%$ of the compression index of tuff.

The recompression curve follows a path almost identical to the rebound curve until the preconsolidation stress of $1 \mathrm{MPa}$ is neared. Beyond $1 \mathrm{MPa}$, the recompression curve should merge with the virgin curve. The virgin, rebound, and recompression values at specific stresses are indicated in Table VII and plotted in Fig. 3. The elastic deformation is even less for crushed tuff than for the Hackroy series. This can be deduced from the lower swelling index and the lower recovery ratio of swelling vs compression for tuff $(0.11 \mathrm{vs} 0.13)$.

As can be seen, the compression modulus is much more variable in the case of crushed tuff than Hackroy series soil and increases fast with stress. Crushed tuff is a very compressible material at low stress but quickly becomes incompressible at higher stress (faster than the Hackroy series soil).

The settlement at a pressure of $1 \mathrm{MPa}$ is, according to Jumikis (1968), equal to $\Delta \mathrm{H}=\mathrm{m}_{\mathrm{v}} \mathrm{H \sigma}$ or, since $\Delta H$ is known.

$\overline{\mathrm{m}}_{\mathrm{v}}=\frac{\Delta \mathrm{H}}{\mathrm{H} \sigma}$,

and

$\bar{M}_{、}=\frac{H \sigma}{\Delta H}=\frac{25.5 \mathrm{~mm} 10^{6} \mathrm{~Pa}}{3.818 \mathrm{~mm}}=6.7 \mathrm{MPa}$

for Hackroy series soil and

$\bar{M}_{v}=\frac{26 \mathrm{~mm} 10^{6} \mathrm{~Pa}}{3.414 \mathrm{~mm}}=7.6 \mathrm{MPa}$

for crushed tuff. Both can be considered fairly compressible materials because they have rather low values of $\mathrm{M}_{\mathrm{v}}$ (Hackroy series soils more so than crushed tuff).

The best fit between hydraulic conductivity, $\mathrm{k}$, and void ratio, E, was determined through regression analysis: $\mathrm{k} \propto 5.51 \cdot 10^{-13} \mathrm{e}^{15.53 \mathrm{E}}$, with $\mathrm{k}$ expressed in $\mathrm{ms}^{-1}$ and $\mathrm{r}=0.97$. It is obvious that the values for the hydraulic conductivity are underestimated at all pressures because of an arbitrarily low choice of $\mathrm{C}_{\mathrm{v}}$.

At a porosity of $0.4(\mathrm{e}=0.67), \mathrm{k}$ would be equal to $1.81 \cdot 10^{-8} \mathrm{~ms}^{-1}$. This is underestimating the measured hydraulic conductivity by a factor of $\sim 80$. The relationship now becomes

TABLE VI

$C_{n}, m_{n}$, AND $k$ AS A FUNCTION OF STRESS FOR CRUSHED TUFF

\begin{tabular}{|c|c|c|c|c|c|}
\hline$\sigma(\mathbf{k P a})$ & $C_{v}\left(m^{2} s^{-1}\right)$ & $m_{v}\left(10^{-8} \mathrm{~Pa}^{-1}\right)$ & $\mathbf{M}_{v}(\mathbf{M P a})$ & $\mathbf{a}_{\mathbf{v}}\left(10^{-8} \mathrm{~Pa}^{-1}\right)$ & $\mathrm{k}\left(10^{-7} \mathrm{~ms}^{-1}\right)$ \\
\hline 60 & $8.7 \cdot 10^{-4}$ & 112.0 & 0.89 & 200.0 & 97.44 \\
\hline 120 & $8.7 \cdot 10^{-4}$ & 32.8 & 3.05 & 57.4 & 28.54 \\
\hline 250 & $8.7 \cdot 10^{-4}$ & 18.0 & 5.56 & 30.8 & 15.66 \\
\hline 500 & $8.7 \cdot 10^{-4}$ & 9.78 & 10.22 & 16.3 & 8.51 \\
\hline 1000 & $8.7 \cdot 10^{-4}$ & 6.03 & 16.58 & 9.75 & 5.25 \\
\hline
\end{tabular}




\section{TABLE VII}

$\mathrm{H}, \triangle \mathrm{e}, \mathrm{e}, \triangle \mathrm{H} / \mathrm{H}$ AS A FUNCTION OF STRESS FOR THE VIRGIN, REBOUND, AND RECOMPRESSION CURVES FOR CRUSHED TUFF

\begin{tabular}{|c|c|c|c|c|}
\hline$\sigma(\mathrm{kPa})$ & $\mathrm{H}(\mathrm{mm})$ & $\Delta \mathbf{e}$ & $\mathbf{e}$ & $\triangle \mathbf{H} / \mathbf{H}$ \\
\hline 60 & -0.874 & -0.06153 & 0.76847 & -0.03362 \\
\hline 120 & -1.386 & -0.09757 & 0.73243 & -0.05331 \\
\hline 250 & -1.994 & -0.14038 & 0.68962 & -0.07669 \\
\hline 500 & $-2.6 \pm 0$ & -0.18515 & 0.64485 & -0.10115 \\
\hline 1000 & -3.414 & -0.24035 & 0.58965 & -0.13131 \\
\hline 250 & -3.264 & -0.22070 & $\because n n ?:$ & $\because: \because=\because$ \\
\hline 60 & -3.142 & -0.22120 & 0.60880 & -0.12085 \\
\hline 250 &.- .242 & -0.22824 & 0.60176 & -0.12469 \\
\hline 800 & -3.374 & -0.23753 & 0.59247 & -0.12977 \\
\hline 1000 & -3.432 & -0.24161 & 0.58839 & -0.13200 \\
\hline
\end{tabular}

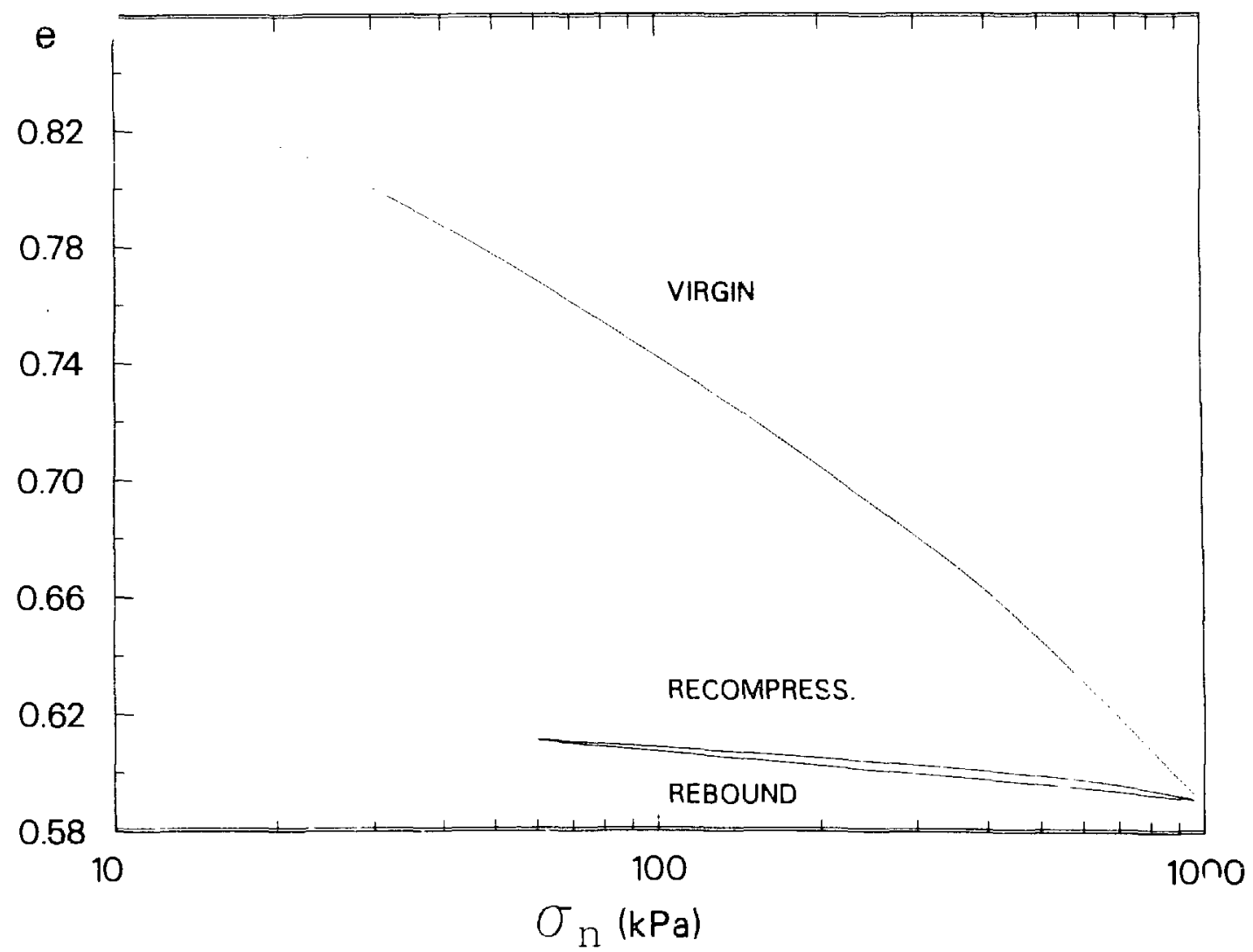

Fig. 3. Virgin, rebound, and recompression curves for crushed tuff. 
$\mathrm{k}=4.37 \cdot 10^{-11} \mathrm{e}^{15.53 \mathrm{E}}$. A more correct $\mathrm{C}_{\mathrm{v}}$ of $8.7 \cdot 10^{-4} \mathrm{~m}^{2} \mathrm{~s}^{-1}$ can now be estimated from the intrinsic relationship between hydraulic conductivity and coefficient of consolidation. Because $\mathrm{k}$ was known, a more direct approach could have been taken by using the formula expressing $C_{v}$ as a function of $k$ and computing $C_{v}$ directly instead of trying to measure it. Our woik also shows that only a static load better than $250 \mathrm{kPa}$ can match the void ratio obtained under dynamic loading in our field experiments.

3. Bentonite/Tuff Mix. The permeability of waste disposal facility iiners and caps, i.e., moisture barriers, is important in geotechnical engineering. Permeability is the dominant parameter in the design and implementation of waste disposal facilities. Clay is prominent among the materials !!sually considered to line or cap disposal pits. Foremost among the problems connected with the use of clays is cracking during periods of desiccation, although both the Environmental Protection Agency (EPA) and the Nuclear Regulatory Commission (NRC) seer 1 to feel that clays, as barriers to water leachate migration and inflow of water, are the principal materials to be considered as liners and caps in waste disposal facilities. Clays and soils, in general, also offer by far the longest service life oi any !iner material.

Use of clay mixes instead of pure clays may be warranted-not solely on the basis of economics; mechanical benefits may even become overriding in mandating the use of mixing. In Lus Alamos, New Mexico, the use of local tuff (texture of sand: silt," Abrahams 1953) with low amounts of bentonite appeared to be very promising in greatly decreasing hydraulic conductivity withuut showing any of the mechanical impairments of clays. Saturated Na-bentonite absorbs water up to 5 times its own mass to form a gel up to 15 times its own dry volume. Besides being less expensive, a liner or cap, consisting of a mix of the local medium and bentonite clay, probably would not crack when desiccated. Cracking from desiccation can be further minimized by proper compaction. A low hydraulic conductivity, combined with acceptable mechanical characteristics, should be obtainable at some ideal nix of two materials, each possessing one or the other property. The objective of this research is to obtain the necessary data to assure that the use of such a mixture (e.g., sandy silt/bentenite) is effective in isolating waste fi om the environment. This research will aiso tell us the respective ratios at which ideal hydraulic and mechanical characteristics may be expected. Laboratory tests were performed at $22^{\circ} \mathrm{C} \pm 2^{\circ} \mathrm{C}$. The bentonite used in our experiments was 13-T and was sbtained from the International Minerals \& Chemical Corporatıon, Des Plaines, Illinois.

One of the liabilities one faces when Lsing Terzaghi's step-loaded method lies in the assumption that $\mathrm{k}, \mathrm{C}_{\mathrm{v}}$ and $\mathrm{m}_{\mathrm{v}}$ remain constant during that particular consolidation load step (Tavenas et al. 1979). Both $C_{v}$ and, mainly, $m_{v}$ show a tendency to decrease with increasirig stress (A. beele 1984) and there is no reason to doubt that the behavior would be different as the void ratio is reduced during any particular consolidation step. Tavenas et al. (i983, Part I) show that the coefficient of consolidation may decrease by more than a factor of 4 during a particular clay consolidation load step. The variability of the coefficient of consolidation with changing stress is not as drastic when the clay content in the soil decreases. No trend in the $C_{v}$ values was detected for any of the lower bentonite/crushed tuff ratios considered in this study. Therefore, the coefficients of consolidation computed for each stress were averaged and used as the mean coefficient of consolidation at a particular mixing ratio. Table VIII shows decreasing $C_{v}$ values with insreasing bentonite/tuff ratios, $R$, whereas the $m_{v}$ values are more susceptible to changing stresses. The relationship between $C$, and $R$ can be written as

$\mathrm{C}_{\mathrm{v}}=0.06 \mathrm{R}^{-2}$,

with $r^{2}=0.99$ for $i 24<R<0.14$

*Sandy silt: an unconsolidated sediment containing $10-50 \%$ sand and having a ratio of silt to clay greater than 2:1 (Folk 1954). 


\section{TABLE VIII}

\section{m, AND A VERAGE $C_{v}$ VALUES FOR $V /$ RYING MIXING RATIOS AND STRESSES}

\begin{tabular}{|c|c|c|c|c|}
\hline \multicolumn{5}{|c|}{$C_{v}\left(10^{-8} m^{2} s^{-1}\right)$} \\
\hline $\mathbf{R}$ & $\sigma(\mathbf{k P a})$ & $\overrightarrow{\mathbf{x}}$ & $\mathbf{s}$ & $m_{v}\left(10^{-6} \mathbf{P a}^{-1}\right)$ \\
\hline \multirow[t]{4}{*}{0.04} & 100 & & & 34.5 \\
\hline & 200 & 41.6 & 6.18 & 20.3 \\
\hline & $4 r \dot{v}$ & & & 12.2 \\
\hline & 800 & & & 7.1 \\
\hline \multirow[t]{4}{*}{0.06} & 100 & & & 39.1 \\
\hline & 200 & 18.2 & 5.90 & 30.2 \\
\hline & 400 & & & 18.1 \\
\hline & 800 & & & 10.0 \\
\hline \multirow[t]{4}{*}{0.075} & 100 & & & 66.3 \\
\hline & 200 & 11.6 & 4.84 & 39.7 \\
\hline & 400 & & & 22.7 \\
\hline & 800 & & & 11.5 \\
\hline \multirow[t]{4}{*}{0.09} & 100 & & & 43.5 \\
\hline & 200 & 8.0 & 6.20 & 37.2 \\
\hline & 400 & & & 22.5 \\
\hline & 800 & & & 14.6 \\
\hline \multirow[t]{4}{*}{0.11} & 100 & & & 40.3 \\
\hline & 200 & 5.3 & 3.29 & 43.0 \\
\hline & 400 & & & 23.4 \\
\hline & 800 & & & 13.6 \\
\hline \multirow[t]{4}{*}{0.14} & 100 & & & 40.0 \\
\hline & 200 & 3.2 & 0.72 & 43.0 \\
\hline & 400 & & & 25.9 \\
\hline & 800 & & & 13.4 \\
\hline
\end{tabular}

To cissure that $C_{v}$ is more or less constant during any load increment, the applied stress increase is never more than double the previous applied stress. Table IV indicates the relationship, based on Eq. (5), of the cornputed values of $\mathrm{k}$ to $\mathrm{R}$ for a particular stress. The computed hydraulic conductivity is expressed in $10^{-10} \mathrm{~ms}^{-1}$.

In view of the liabilities we encountered when deriving hydraulic conductivity by application of the consolidation method and considering the difficulties in determining the coefficient of consolidation at lower bentonite contents $(<0.01)$, direct measurement of conductivity was also performed using the constant head meinod. At low bentonite ratios, the consolidation rate is too fast to be measured with any degree of accuracy.

During consolidation of pure crusned tuff (sandy silt), the void ratio-log time curves were concave upward from the start, indicating extremely fast consolidation and subsequent low degree of accuracy. The coefficient of consolidation averaged $8.7 \cdot 10^{-4} \mathrm{~m}^{2} \mathrm{~s}^{-1}$ for repetitive stresses of 50 , $100,200,400$, and $800 \mathrm{kPa}$. $A_{\mathrm{n}} \mathrm{n}$ analysis of variance detected no trend in $\mathrm{C}_{\mathrm{v}}$ with increasing stress because of the high values of the standard deviations for $\mathrm{C}_{v}$ at $0 \%$ bentonite. The conductivities 
obtained using the constant head method on uncompacted tuff $(0 \mathrm{kPa})$ with low bentonite ratios $(0-0.04)$ are in general agreement with the results obtained using the consolidation method for higher bentonite ratios (0.04-0.14). This is demonstrated in Fig. 4.

Table IX shows, for varying consulidation pressures, the close power relationship existing between $\mathrm{R}$ as independent variable and $\mathrm{k}$ as dependent variable (all $r^{2}$ are better than 0.99 !). That trend is disnlayed linearly on a $\log -\log$ plot in Fig. 5, with $\mathrm{k}$ decreasing with increasing clay fraction. Figure 5 contains orly the results obtained using the consolidation method and $R$ values varying from 0.04 to 0.14 . The results obtained using the constant head method $(0 \mathrm{kPa})$ are not shown in Fig. 5 because the regression equation showing the best fit is not a power finction. The best fit for uncompacted mixed $(\mathrm{R}=0$ to 0.04$)$ is $\log \mathrm{k}=5.065-94.298 \mathrm{R}$, with $\mathrm{r}^{2}=0.982$ and $\mathrm{k}$ in $10^{-10} \mathrm{~m} \mathrm{~s}^{-1}$. Figures 4 and 5 further demcnstrate that hydraulic conductivity is not only a function of particle size distribution or varying bentonite ratio, but also of void ratio (or applied stress). The conductivity of a porous materiai obviously decreases with void ratio, $e$, and $e$, in turn, decreases with increasing compaction pressure or stress, $\sigma$. The former is clearly shown in Table X and Fig. 6 . Direct measurement of hydraulic conductivity using either the constant head method or the consolidation method produres a linear e vs log $\mathrm{k}$ relationship. A predictive empirical linear relationship between $\log \mathrm{k}$ and e was first proposed by Taylor (1948)

$\log k=\log k_{o}-\frac{e_{o}-e}{C_{k}}$.

where $k_{o}$ and $e_{o}$ inay be in situ, remolded, or known preconsolidated values and $C_{k}$ is a permeability change index. This type of relationship has become regarded as the most accurate way of expressing the variation of permeability with void ratio (Tavenas et al. 1983, Part II). The linear relationship between $\log \mathrm{k}$ and e extends beyond strains of $20 \%$ for sandy silt/bentonite mixes, whereas Tavenas et al. (1983, Part Ir) limit the validity of this relationship to strains of less than $20 \%$ for most natural soft clays.

The interrelationship between $\log \mathrm{k}$ and $\mathrm{e}$ is very important in the study of materials in caps or liners that can in any way influence the migration of pollutants from waste disposal pits. Indeed, in a homogenizi,d material with uniform grain size distribution (as the one likely to be used to line or cap a waste $\mathrm{a}$ isposal pit), the porosity would be the only variable to influence the condictivity. The slope of the void ratio vs $\log \mathrm{k}$ is defined as the permeability change index, $\mathrm{C}_{\mathrm{k}}$ (Tavenas et al. 1983, Part II). Table XI seems to indicate that the permeability change index, $C_{k}$, and the compression index, $C_{c}$, are both increasing with increasing bentonite ratio. (The compression index, $C_{c}$, is the slope of the straight line where $\left.e=-C_{c} \log \sigma / \sigma_{0}\right)$. The values for the $C_{c} / C_{k}$ ratio average 0.677 , with $\mathrm{s}=0.035$ or a CV (coefficient of variation) of $5.1 \%$.

A linear relationship can be esiablished between $C_{k}$ and $C_{c}$ with

$C_{k}=-0.053+1.706 C_{c}$,

with $r^{2}=0.983$.

For sandy silt/bentonite mixes, $C_{k}$ relates to $e_{o}$ as

$C_{k}=-0.835+1.585 \mathrm{e}_{\mathrm{n}}$.

No apparent relationship seems to link the $C_{c} / C_{k}$ ratio with the void ratio, e.

According to Tavenas et al. (1983, Part II), the condition for a constant $C_{v}$ during consolidation may be written

$\frac{1}{C_{c}}-\frac{1}{C_{k}}=\frac{1}{1+e_{o}}$. 


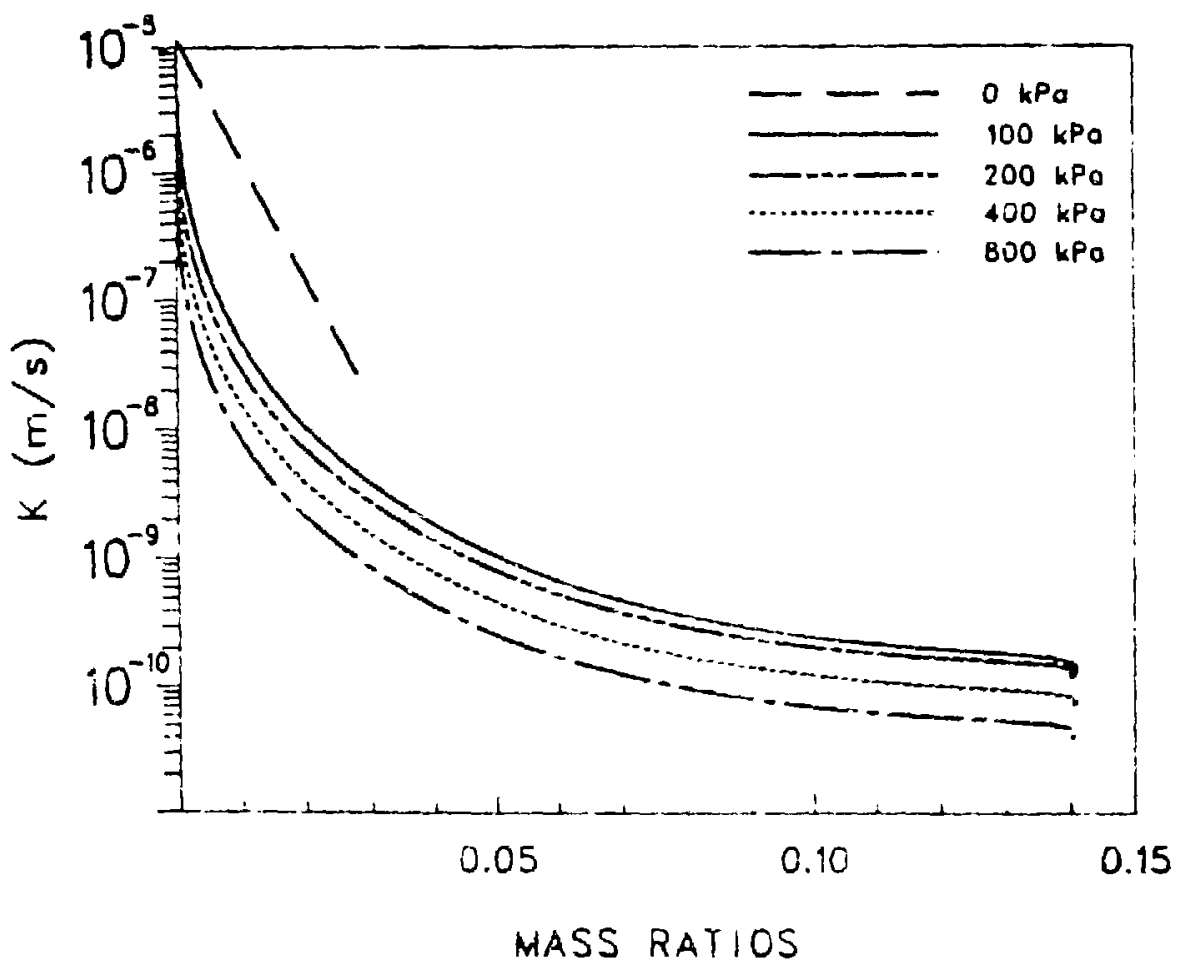

Fig. 4. Hydraulic conductivity as a function of bentonite/sandy silt ratios.

\section{TABLE IX}

\section{SATURATED HYDRAULIC CONDUCTIVITY $\left(10^{-10} \mathrm{~ms}^{-1}\right)$ EXPRESSED AS A FUNCTION OF MIXING RATIOS FOR DIFFERENT CONSOLIDATION PRESSURES}

\begin{tabular}{|c|c|c|}
\hline $\begin{array}{l}\text { Stress } \\
\text { (kPa) }\end{array}$ & k & $r^{2}$ \\
\hline 100 & $0.021 R^{-2.098}$ & 0.996 \\
\hline 200 & $0.024 R^{-1.968}$ & 0.995 \\
\hline 400 & $0.015 R^{-1.934}$ & 0.996 \\
\hline 800 & $0.009 \mathbf{R}^{-1.910}$ & 0.996 \\
\hline
\end{tabular}




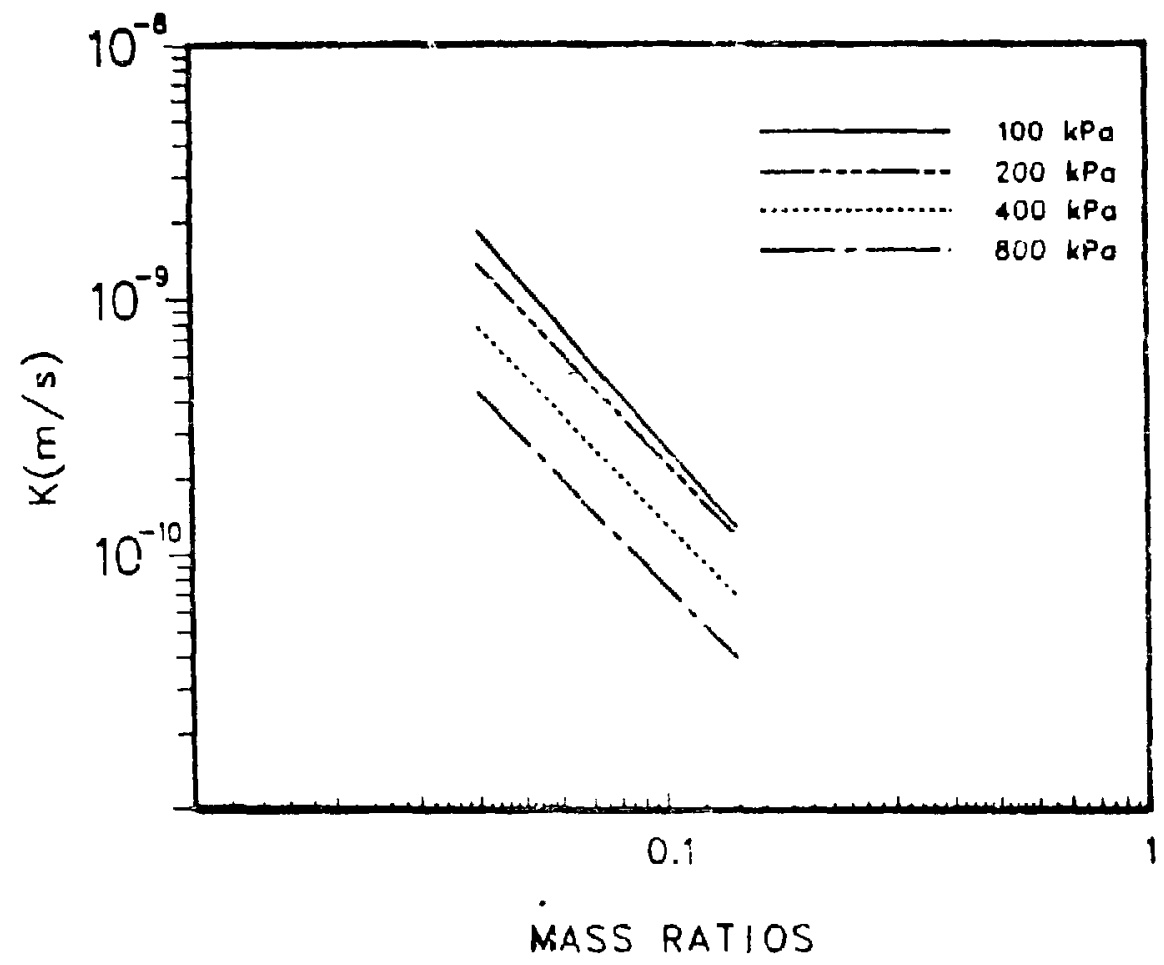

Fig. J. Hydraulic conductivity as a function of bentonite/sandy silt ratios.

\section{TABLE X}

\section{HYDRAULIC CONDUCTIVITY (in $10^{-12} \mathrm{~ms}^{-1}$ ) AS A FUNCTION OF VOID RATIOS FOR VARYING CLAY CONTENTS}

\begin{tabular}{lccc}
$\frac{\mathbf{P}}{0.00}$ & \multicolumn{1}{c}{$\log \mathbf{k}$} & & $\mathbf{r}^{2}$ \\
0.04 & $2.722 \mathrm{e}+4.499$ & & 0.846 \\
0.06 & $4.893 \mathrm{e}+0.406$ & & 0.980 \\
0.075 & $3.871 \mathrm{e}+0.132$ & & 1.000 \\
0.09 & $2.519 \mathrm{e}+0.918$ & & 0.965 \\
0.11 & $2.274 \mathrm{e}+0.814$ & & 0.960 \\
0.14 & $2.107 \mathrm{e}+0.713$ & & 0.954 \\
& $1.916 \mathrm{e}+0.559$ & & 0.946
\end{tabular}




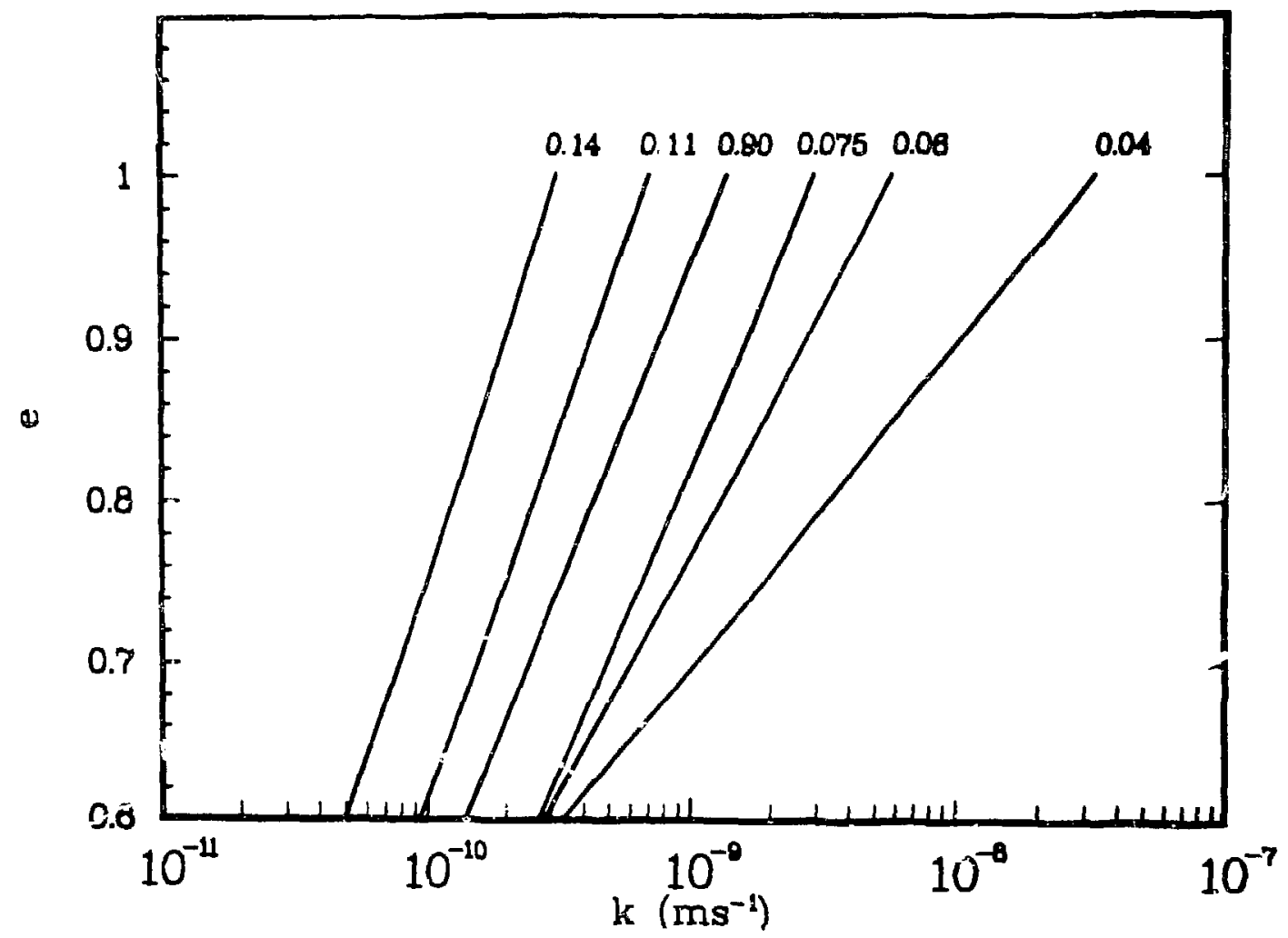

Fig. 6. Hydraulic conductivity as a function of void ratios for varying clay contents.

TABLE XI

COMPRESSION INDEX, PERMEABILITY CHANGE INDEX, AND DERIVED RELATIONSHIPS AS A FUNCTION OF CLAY RATIOS

\begin{tabular}{|c|c|c|c|c|c|}
\hline $\mathbf{R}$ & $\mathrm{C}_{\mathrm{e}}$ & $C_{k}$ & $\mathrm{C}_{\mathrm{c}} / \mathrm{C}_{\mathrm{k}}$ & $\left(1 / C_{c}-1 / C_{k}\right)$ & $1 /\left(1+e_{0}\right)$ \\
\hline 0.04 & 0.145 & 0.200 & 0.722 & 1.926 & 0.569 \\
\hline 0.06 & 0.210 & 0.304 & 0.692 & 1.463 & 0.571 \\
\hline 0.075 & 0.259 & 0.383 & 0.676 & 1.251 & 0.581 \\
\hline 0.09 & 0.280 & 0.401 & 0.697 & 1.084 & 0.564 \\
\hline 0.11 & 0.292 & 0.453 & 0.646 & 1.213 & 0.557 \\
\hline 0.14 & 0.311 & 0.494 & 0.629 & 1.196 & 0.542 \\
\hline
\end{tabular}


As can be seen from Table XI, the left side of the equation exceeds the right side by a factor of 2 or 3 , thus failing once more to validate Terzaghi's assumption of the constancy of $\mathrm{C}_{\mathrm{v}}$ during any particular loading step. This requirement had to be fulfilled for the consolidation method to be valid for the computation of $\mathrm{k}$. However, our practical results using the consolidation method show a good compatibility with the results obtained using the constant head method or with the ones obtained by Daniel and Olson (1980) when using the same materials (tuff + bentonite). In fact, the results obtained by Daniel and Olson at $0 \mathrm{kPa}$ are identical to our results at $400 \mathrm{kPa}$.

The predictive empirical linear relationship between log $\mathrm{k}$ and e first proposed by Taylor (1948) [Eq. (9)] allows us to compare the predicted (Taylor) vs measured hydraulic conductivities (in $10^{-12} \mathrm{~ms}^{-1}$ ) using the consolidation method. In no case did the discrepancy between the two methods amount to $3.5 \%$ when evaluated for the highest applied stress (see Table XII).

The consolidation data were readily available because the computation of the hydraulic conductivity, in accordance with Terzaghi's theory, required measurement of the consolidation. Table XIII shows how the void ratio, $\mathrm{e}$, varies as a function of stress, $\sigma$ (or pressure), for different bentonite ratios, $R$. The goodness of fit of the data to the equation is expressed by the coefficient of determination $r_{c}^{2}(\log \sigma)$.

$\mathrm{C}_{\mathrm{c}}$ and $\mathrm{S}_{\mathrm{c}}$ are the consulidation and swelling indices obtained for different bentonite ratios. Figure 7 shows how both increase with increasing bentonite ratios. The $S_{c} / C_{c}$ ratio averages 0.117 , with a standard deviation of 0.018 , or a coefficient of variation close to $16 \%$. A linear relationship established between $S_{c}$ and $C_{c}$ yields $S_{c}=-0.005+0.140 C_{c}$ and $r^{2}=0.823$.

\section{B. Consolida: ' Drained (CD), Shear Test}

When soil interfaces or surfaces are not horizontal, gravity will tend to slump a given soil mass downward. If an external force, siatic or dynamic in nature, joins with gravity, the shear stress along a soil interface or crack or any potential slip surface may cause rupture and subsequent movement of a given soil mass. This is the reason that shear strength in rocks and soils should always be evaluated before being submitted to a shear stress resulting from slopes created by excavations and aggravated by additional stresses (water movemerit, static or dyramic loads contrived by nature or man).

Negative stress induced by capillary tension will be at the origin of increased soil shear strength. Capillary tension is the úriving force that enables moist sand to maintain a molded or cut shape. Thin water films with small meniscus radii develop high tensile stresses in the moisture wedges that hold soil particles in rigid contact. Fine sands and silts above a water table owe their strength to capillary tension and the resulting effective stresses in the granular structure. A point of maximum stress exists as a function of moisture content for a particular soil. In that case, any drying or wetting away from that optimum moisture content will mean a decrease in maximum

\section{TABLE XII}

\section{PREDICTED (TAYLOR) AND MEASURED HYDRAULIC CONDUCTIVITIES (in $10^{-12} \mathrm{~ms}^{-1}$ ) AT $800 \mathrm{kPa}$ FOR VARYING CLAY RATIOS}

\begin{tabular}{|c|c|c|c|}
\hline $\mathbf{R}$ & $\begin{array}{c}\mathbf{k} \\
\text { Predicted }\end{array}$ & $\begin{array}{c}\mathbf{k} \\
\text { Measured }\end{array}$ & $\frac{K_{\mathrm{m}}-\mathbf{K}_{\mathrm{p}}}{\mathbf{k}_{\mathrm{m}}}$ \\
\hline 0.04 & 2.613 & 2.636 & 0.007 \\
\hline 0.06 & 2.270 & 2.299 & 0.013 \\
\hline 0.075 & 2.081 & 2.114 & 0.016 \\
\hline 0.09 & 1.896 & 1.964 & 0.035 \\
\hline 0.11 & 1.759 & 1.799 & 0.022 \\
\hline 0.14 & 1.626 & 1.602 & -0.015 \\
\hline
\end{tabular}




\section{TABLE XIII}

\section{CONSOLIDATION AND SWELLING OF}

BENTONIT:/SANDY SILT MIXES

\begin{tabular}{|c|c|c|c|c|c|}
\hline $\mathbf{R}$ & e & $r^{2} e(\log \sigma)$ & $\mathrm{C}_{\mathrm{c}}$ & $\mathbf{S}_{\mathrm{c}}$ & $\mathrm{S}_{\mathrm{c}} / \mathrm{C}_{\mathrm{c}}$ \\
\hline 0.00 & $0.915-0.129 \log \sigma$ & 0.993 & 0.129 & 0.016 & 0.108 \\
\hline 0.04 & $1.047-0.145 \log \sigma$ & 0.994 & 0.145 & 0.018 & 0.121 \\
\hline 0.06 & $1.171-0.210 \log \sigma$ & 0.996 & 0.210 & 0.021 & 0.101 \\
\hline 0.075 & $1.240-0.259 \mathrm{log}-$ & 0.999 & 0.259 & 0.025 & 0.096 \\
\hline 0.09 & $1.333-0.280 \log \sigma$ & 0.990 & 0.280 & 0.033 & 0.119 \\
\hline 0.11 & $1.381-0.292 \log \sigma$ & 0.997 & 0.292 & 0.035 & 0.121 \\
\hline 0.14 & $1.465-0.311 \log \sigma$ & 0.998 & 0.311 & 0.047 & 0.151 \\
\hline
\end{tabular}

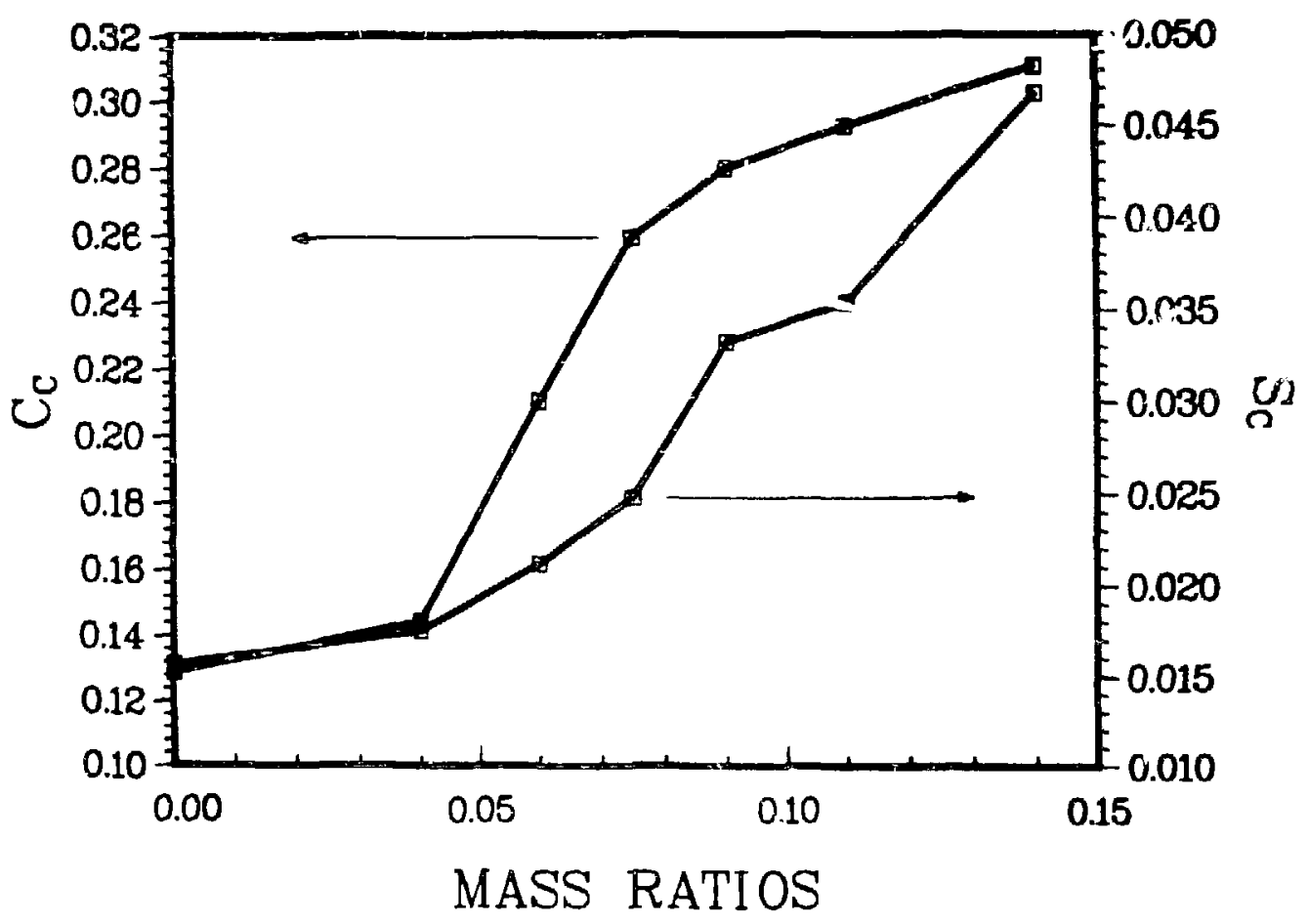

Fig. 7. Consolidation and swelling indices as a function of bentonite/sandy silt ratios. 
or more resulting stress-strain graphs obtained for the three or more applied normal stresses shows a peak shear stress. The peak shear strengths are then plotted as a function of the effective normai stresses. The shear strength is then expressed analytically in the Cuulomb equation,

$\tau=\sigma_{\mathrm{n}_{\mathrm{eff}}} \tan \varphi+\mathrm{C}$.

Coulomb's equation shows that the shearing resistance is made up of the following two components.

(1) Friction, increasing with normal stress $\left(\tau=\sigma_{n_{\text {eff }}}\right)$ caused by the interlocking of particles. Sand is a good example of a frictional and cohesionless soil. The Coulomb failure envelope passes through the origin.

(2) Cohesion, independent of normal stress. Coulomb's failure envelope is virtualiy horizontal if saturated clay is not allowed to consolidate before or drair during shearing.

In the tests involving Hackroy series soils, no sharp peak is apparent when plotting $\tau$ against horizontal displacement.

The volume decreased continuously during shearing, although in far !esser amourts if shearing was preceded by higher level preconsolidation. In no case was there any dilatancy.

Saturated, unpreconsolidated Hackroy szries soil has a shearing strength of

$$
\tau=25.89+0.621 \sigma_{n} \quad r^{2}=0.99948 \text {. }
$$

whereas saturated Hackroy series soil proconsolidated at $500 \mathrm{kPa}$ had a shearing strerigth of

$$
\tau=33.17+0.618 \sigma_{\mathrm{n}} \quad r^{2}=0.99914
$$

For crushed tuff, no distinct peak was apparent. Virtually no decrease in shear stress with increased displacement was noticed after the ultimate shear stress was attained. Unpreconsolidated crushed tuff decreases in volume upon shearing, a behavior reminiscent of loose sand. That behavior changes if the sample is preconsolidated, and dilatancy occurs only if the preconsolidated sample is sheared in a submerged shearbox.

For saturated, unpreconsolidated crushed tuff, moisture ratio by volume (MRV) $=0.453$, and dry density $(\gamma \mathrm{d})=1.40 \mathrm{Mg} \mathrm{m}^{-3}$

$$
\tau=8.72+0.73 \sigma_{\mathrm{n}} \quad r^{2}=0.99770 .
$$

For saturated crushed tuff preconsolidated at $1 \mathrm{MPa}, \mathrm{MRV}=0.349$ and dry unit weight $(\gamma \mathrm{d})=$ $1.667 \mathrm{Mg} \mathrm{m}^{-3}$

$$
\tau=23.48+0.819 \sigma_{\mathfrak{n}} \quad r^{2}=0.99279 .
$$

In comparing Hackroy series soil with crushed tuff, it is immediately obvious that the soils have a higher apparent cohesion, whereas tuff has a higher coefficient of internal friction. The angle of repose, representing the angle of internal friction of a granular material at its luosest state, can be calculated from Coulomb's envelope. It amounts to $38^{\circ}$ for crushed tuff and $32^{\circ}$ for Hackroy series soils (when cohesion is no factor, as when dry and remolded). The repose angle of crushed tuff, which is higher than the normally expected range $\left(30^{\circ}-35^{\circ}\right)$, is probably mainly due to a higher than average angularity, surface roughness, and grain size distribution, all of which will tend to increase that angle of repose. However, as the intemal friction angle is within the expected value range, the apparent cohesion is invariably higher than expected.

Table XIV shows how the average secant elasticity module of both Hackroy series soil (HSS) and crushed Bandelier tuff(CBT) vary with stress. The data are not $100 \%$ accurate since they were read from a direct shear test with $\sigma_{\max }=500 \mathrm{kPa}$ instead of a triaxal test. 
or more resulting stress-strain graphs obtained for the three or more applied normal stresses shows a peak shear stress. The peak shear strengths are then plotted as a function of the effective normai stresses. The shear suragth is then expressed analytically in the Coulomb equation,

$\tau=\sigma_{\mathrm{n}_{\mathrm{eff}}} \tan \varphi+\mathrm{C}$

Coulomb's equation shows that the shearing resistance is made up of the following two components.

(1) Friction, increasing with normal $; i, j=\sigma_{n_{\text {eff }}}$ ) caused by the interlocking of particles. Sand is a good example of a frictiona! und cohesionless soil. The Coulomb failure envelope passes through the i igin.

(2) Cohesion, independent of normal stress. Coulomb's failure en velope is virtually horizon-

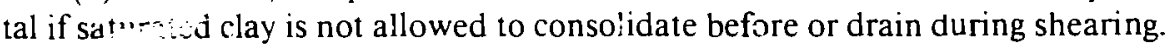

in the tests involving Hackroy series soils, no sharp peak is apparent when plotting $\tau$ against horizontal displacement.

The volume decreased continuously during shearing, although in far lesser amourts if shearing was precederi by higher level preconsolidiotion. In no case was there any dilatancy.

Saturated, unpreconsolidated Hackroy series soil has a shearing strength of

$$
\tau=25.89+0.621 \mathrm{C}_{\mathrm{n}} \quad \mathrm{r}^{2}=0.99948
$$

whereas saturated Hackroy series soil preconsolidated at $500 \mathrm{kPa}$ had a shearing strength of

$$
\tau=33.17+0.618 \sigma_{\mathrm{n}} \quad r^{2}=0.99914 .
$$

For crushed tuff, no distinct peak was apparent. Virtually no decrease in shear stress with increased displacement was noticed after the ultimate shear stress was attained. Unpreconsolidated crushed tuff decreases in volume upon shearing, a behavior reminiscent of loose sand. That behavior changes if the sample is preconsolidated, and dilatancy occurs only if the preconsolidated sample is sheared in a submerged shearbox.

For saturated, unpreconsolidated crushed tuff, moisture ratio by volume (MRV) $=0.453$, and dry density $(\gamma \mathrm{d})=1.40 \mathrm{Mg} \mathrm{m}^{-3}$

$$
\tau=8.72+0.73 \sigma_{n} \quad r^{2}=0.99770
$$

For saturated crushed tuff preconsolidated at ! MPa, MRV $=0.349$ and dry unit weight $(\gamma \mathrm{d})=$ $1.667 \mathrm{Mg} \mathrm{m}^{-3}$

$$
\tau=23.48+0.819 \sigma_{\mathrm{n}} \quad \mathbf{r}^{2}=0.99279
$$

In comparing Hackroy series soil with crushed tuff, it is immediately obvious that the soils have a higher apparent cohesion, whereas tuff has a higher coefficient of in ternal friction. The angle of repose, representing the angle of internal friction of a granular material at its loosest state, can be calculated from Coulomb's envelope. It amounts to $38^{\circ}$ for crushed tuff and $32^{\circ}$ for Hackroy series soils (when cohesion is no factor, as when dry and remolded). The repose angle of crushed tuff, which is higher than the normally expected range $\left(30^{\circ}-35^{\circ}\right)$, is probably mainly due to a higher than average angularity, surface roughness, and grain size distribution, all of which will tend to increase that angle of repose. However, as the internal friction angle is within the expected value range, the apparent cohesion is invariably higher than expected.

Table XIV shows how the average secant elasticity module of both Hackroy series soil (HSS) and crushed Bandelier tuff (CBT) vary with stress. The data are not $100 \%$ accurate since they were read from a direct shear test with $\sigma_{\operatorname{mar}}=500 \mathrm{kPa}$ instead of a triaxal test. 
TABLE XIV

\section{ELASTICITY MODULUS AS A FUNCTION OF STRESS}

\begin{tabular}{|c|c|c|}
\hline$\sigma(\mathbf{k P a})$ & $\begin{array}{c}\text { HSS } \\
\text { E(MPa) }\end{array}$ & $\begin{array}{c}\text { CBT } \\
\mathrm{E}(\mathrm{MPa})\end{array}$ \\
\hline 100 & 21 & 22 \\
\hline 200 & 20 & 22 \\
\hline 300 & 17 & 21 \\
\hline
\end{tabular}

\section{Resistance to Penetration}

Resistance to the penetration of a probing instrument is an integrated index of compaction, moisture content and type of material involved (crushed tuff, various clays, sand, etc.). As a penetrometer enters the soil, it will encounter resistance to compression, some friction between soil and metal, and the shear resistance of the soil, which, as described above, involves both internal friction and cohesion (Baver et al. 1972).

1. Rod-Shaped Laboratory Penetrometer. If left to desiccate from a saturated state, the resistance to penetration increases in both tuff and soils (Tables XV and XVI). At very low moisture content ( $2 \%$ ), the attraction between particles breaks down completely in tuff, whercas it continues to increase in the Hackroy series soils, reaching its maximum at the lowest moisture content. Turf regains its complete loosc state at $1 \%$ moisture content. This is quite similar to results obtained on sands where zero shear strengths are apparent when sands are either dry or saturated. A small cohesion is even observed in moist sánd because of surface tension (Head 1982).

Just as the shear strength of crushed tuff at a given moisture content is very much a function of its dry density, so is the strength of undisturbed or solid tuff equally dependent on its dersity (Purtymun and Koopman 1965). For several sites in the Los Alamos area, the influences of densily (D) on crushing resistance (CR) can be expressed as

$$
C R=-383+51.72 \ln \mathrm{D} \text {. }
$$

where the resistance to crushing is expressed in MPa and the bulk density in $\mathrm{kg} \mathrm{m}^{-3}$.

2. Dutch Cone Static Field Pencitrometer. The shape of this instrument precludes the influence of penetration depth on penetration resistance. This can be regarded as a distinct advantage over the pocket or laboratory penetrometer. The disadvantage of the Dutch Cone penetrometer is its size, which limits its application to field experiments. Moisture contents were measured but not controlled. This penetrometer measures a complexity of soil conditions varying from moisture content to soil gradation, density, friction, cohesion, etc.

According to Sowers (1979), the undrained strength can be roughly approximated by $C=P / N$ where $\mathrm{P}$ is the measured point resistance and $\mathrm{N}$ embodies the shape of the device. Values for $\mathrm{N}$ range between 5 and 15 for the Dutch Cone penetrometer, depending on sensitivity of the soil (very sensitive soils require a low $\mathrm{N}$ value). Taking $\mathrm{N}$ arbitrarily equal to 10 yields an average cohesion of $122.25 \mathrm{kPa}$ with $\mathrm{s}=33.66 \mathrm{kPa}$ for undisturbed consolidated Hackroy series soil and $20.63 \mathrm{kPa}$ with $\mathrm{s}=4.96 \mathrm{kPa}$ for disturbed soil.

\section{Vane Shear Test}

The cohesion component can be obtained in the oid using the vane shear test. Becarise the friction component is not measured (this would imply the application of increasing normal 
TABLE XV

\section{RESISTANCE TO PENETRATION IN TUFF AFTER PUDDLING}

$\begin{array}{crr}\begin{array}{c}\mathbf{H}_{2} \mathbf{O} \\ (\%)\end{array} & & \begin{array}{c}\mathbf{R P} \\ (\mathbf{k P a})\end{array} \\ 28 & & 0 \\ 25 & & 15 \\ 20 & & 300 \\ 9 & & 420 \\ 10.5 & & 430 \\ 8.5 & & 440 \\ 6.5 & & 450 \\ 6 & & 460 \\ 2 & & 50 \\ 1 & & 15\end{array}$

TABLE XVI

\section{RESISTANCE TO PENETRATION IN SOIL AFTER REMOLDING}

$\begin{array}{crr}\begin{array}{c}\mathbf{H}_{2} \mathbf{O} \\ (\%)\end{array} & & \begin{array}{c}\mathbf{R P} \\ (\mathbf{k P a})\end{array} \\ 28 & & 1 \\ 25 & & 1 \\ 17 & & 100 \\ 16 & & 150 \\ 14 & & 400 \\ 13 & & 450 \\ 12 & & 460 \\ 11 & & 475 \\ 9.5 & & 500 \\ 2 & & >500 \\ 1 & & >>500\end{array}$

stresses), cohesion can be determined from a single measurement. The vane shear test is capable of performing on undisturbed samples what the unconsolidated, undrained test achieves in the laboratory. In the vane shear tes?, the vane is driven at the desired depth into the soil and rotated. The torque for shearing is measured. The shear area is thecretically equal to that of the cylinder formed by the shearing action of the blade edges. The theoretical relationship existing among blade dimensions, torque, $T$, and cohesion is

$\mathrm{T}=\frac{4 \pi \mathrm{r}^{2} \mathrm{C}}{1000}\left(\frac{\mathrm{H}}{2}+\frac{\mathrm{r}}{3}\right)$

OT

$C=\frac{1000 T}{4 \pi r^{2}\left(\frac{H}{2}+\frac{r}{3}\right)}$

if $\mathrm{C}$ is expressed in $\mathrm{kPa}$ and the blade dimensions in $\mathrm{mm}$.

For the standard height to radius ratio of 4.

$C=\frac{1000 \mathrm{~T}}{28 / 3 \pi r^{3}}$

If $\mathrm{r}=10 \mathrm{~mm}$ (Roctest's standard blade).

$\mathrm{C}=\frac{3 \cdot 10^{3} \mathrm{~T}}{28 \cdot 10^{3}}=0.0341 \mathrm{~T}$

The advantage of the vane shear test is that the cohesion profile of an undisturbed sril can rapidly be obtained. 
The remolded vane shear strength is determined in situ after the vane has been rotatec a minimum of lu times in undisturbed soil. Remolding is used to determine the soil's sensitivity - the ratio of undrained strengths (undisturbed/remolded) due to disturbance. After a period of rest, thixotropy will add strength to the remolded specimen.

Cohesion measurements of the Hackroy series soils are compared in Table XVII. Disturbed soil samples refer to those broken up by heavy machinery and moved to an experimental plot.

The measured sensitivity was 2.62 , which is a low to medium sensitivity. The undisturbed, consolidated tests refer to the field shear vane testing of soils where heavy machinery and/or a high pile of cobbles had been deposited for a certain length of time while the upper soil layer was saturated.

\section{TABLE XVII}

\section{COHESIVENESS OF HACKROY SERIES SOIL}

\begin{tabular}{|c|c|c|c|c|}
\hline & \multicolumn{2}{|c|}{$\tau(\mathrm{kPa})$} & \multicolumn{2}{|c|}{ Sensitivity } \\
\hline & $\overline{\mathrm{X}}$ & $\mathbf{s}$ & $\overline{\mathrm{X}}$ & $\mathbf{s}$ \\
\hline Undisturbed, unconsolidated & 44.50 & 6.67 & 2.62 & 0.09 \\
\hline I.D. remolded & 17.00 & 1.41 & & \\
\hline Undicturhad, consolidated & I I 8.00 & 46.90 & & \\
\hline Disturbed & 17.33 & 4.68 & & \\
\hline Shearbox & 25.89 & & & \\
\hline $\begin{array}{l}\text { Shearbox: consolidated } \\
\qquad 500 \mathrm{kPa}\end{array}$ & 33.17 & & & \\
\hline
\end{tabular}

\section{PROGNOSIS}

\section{A. Tests in Use}

Aside from the tes... performed in Los Alamos to study soil stability, a number of tests are more specifically intenued to predict settlement in granular materials. These are the cone penetrometer test, discussed above, the plate-bearing test, and the standard penetration test. A short review of the two latter tests follows.

1. Plate-Bearing Test. This test consists of a series of incremental loads with simultaneous measurements of the corresponding settlements of the soil area under stress. Field settlement can be predicted as being inversely proportional to the ratio of field/plate radius or width. Corrections havc to be made for deep uniform deposits because of an increase of the elasticity modulus with depth. Terzaghi and Peck (1974) propose the following correction for settlement prediction if a plate with a $0.3 \mathrm{~m}$ square is used:

$\Delta H-1 H_{0}\left(\frac{6.56 \mathrm{~B}}{3.28 \mathrm{~B}+1}\right)^{2}$

where

$\Delta \mathrm{H}=$ predicted settlement under pressure, $\mathrm{p}$,

$\Delta \mathrm{H}_{\mathrm{o}}=$ settlement of $0.3 \mathrm{~m}$ square test plate under pressure, $\mathrm{p}$, and

$\mathrm{B}=$ width of waste trench in meters. 
Resistance to settlement will depend significantly on the internal friction angle, $\varphi$, which in turn is strongly dependent on the relative density: a well compacted soil will settle iess than a loose soil. The elasticity modulus is the soil property that most significantly influences settlement under high pressure.

2. Standard Penetration Test. This is the most commonly used field penetration test and entails the determination of the numbers of blows, $N$, required to drive a given split spoon sampler driven by a particular mass dropped from a predetermined height over a certain distance. Peck et al. (1974) relate allowable net bearing pressure, $p$ (in $\mathrm{kPa}$ ), to settlement, $\Delta \mathrm{H}$ (in $\mathrm{mm}$ ), as:

$\mathrm{p}=0.41 \mathrm{~N} \Delta \mathrm{H}$

It is well known that for a granular soil, the penetration resistance is strongly correlated with the relative density of the material under stress. The above formula will also have to be corrected for overburden pressure since it has been shown (Peck et al. 1974) that the standard penetration blow count increased with increasing effective overburden pressure. The correction factor

$C_{F}=0.77 \log \frac{1915}{\sigma}$

with $\sigma$ in $\mathrm{kPa}$.

As an example, let us assume that we want to determine the allowable load at a depth of $8 \mathrm{~m}$ in a sanciy silt if the blow count is 30 blows per $0.30 \mathrm{~m}$. The wet density is 1.6 and we want to limit the settlement to $100 \mathrm{~mm}$.

Weight of set soil: $1.6 \times 1000 \mathrm{~kg} \mathrm{~m}^{-3} \times 9.81 \mathrm{~m} \mathrm{~s}^{-2}=15.7 \mathrm{kN} \mathrm{m}^{-3}$.

Overburden pressure: $15.7 \mathrm{kN} \mathrm{m}^{-3} \times 8 \mathrm{~m}=126 \mathrm{kPa}$.

$C_{F}=0.77 \log \frac{1915}{126}=0.91$.

The corrected blow count for overburden pressure is $0.91 \times 30=27$.

The allowable load is $0.41 \times 27 \times 100=1107 \mathrm{kPa}=1.1 \mathrm{MPa}$.

A pressure of $1.1 \mathrm{MPa}$ will, consequently, bring a settlement of $100 \mathrm{~mm}$ about. We must remember, however, that any theoretical estimate of settlement is an approximation because soils are nct strictly elastic, homogeneous, and isotropic. The best estimates of settlement can be obtained by using. ac ording to Lambe and Whitman (1979):

1. Elastic theories to estimate stresses.

2. Obtaining s1 ains or elasticity moduli.

3. Relying upon experience to compensate for sample disturbance.

\section{B. Settlement}

Settlements causing damage have been categorized as (1) total settlement, (2) differential settlement, and (3) siope of settlement curve.

Work by Grant et al. (1974) seems to point out a correlation between total settlement, $\Delta H$, and slope of the settlement curve, $d(\Delta \mathrm{H}) / \mathrm{dx}$, and also a correlation between differential setilement, $\partial$, and the slope of the settlement curve $d(\Delta \mathrm{H}) / \mathrm{dx}$. They relate as (Dunn et al. 1980): 
For clay

$\Delta H=1200-\frac{d(\Delta H)}{d x}$

$\delta=650 \frac{\mathrm{d}(\Delta \mathrm{H})}{\mathrm{dx}}$

For Sand

$$
\begin{aligned}
& \Delta H=600 \frac{d(\Delta H)}{d x} \\
& \delta=350 \frac{d(\Delta H)}{d x}
\end{aligned}
$$

Based on these correlations, it is conceivable to use any of the above as independent variables for the computation of any other two dependent variables to serve as settlement criteria. For example, if our allowable total settlement for the sandy silt in use remains $100 \mathrm{~mm}$, the settlement slope should not exceed 0.17 , whereas the differential settlement should remain below $58 \mathrm{~mm}$.

Prediction of soil settlement would be a simple affair if the criteria of elasticity, homogeneity, and isotropicity were filly satisfied. This rarely being the case, the elastic theory only serves as a guide in settlement predictions and, despite the fact that the elastic modulus generally increases with depth, it plays a key role in any settlement computation.

Suppose an 8-m depth of fill is placed over loose sandy silt, located high above the water table and having a unit weight of $13.7 \mathrm{kN} \mathrm{m}^{-3}$. We are asked to predict the settlement of an underlying layer of $10 \mathrm{~m}$ of that sandy silt if the same material is used as backfill:

At mid-depth in the sand, the stress, $\sigma=5 \mathrm{~m} \times 13.7 \mathrm{kN} \mathrm{m}^{-3}=68.6 \mathrm{kPd}$.

The stress increase $\Delta \sigma=8 \mathrm{~m} \times 13.7 \mathrm{k} \mathrm{Nm}^{-3}=110 \mathrm{kPa}$.

Final stress at mid-depth $\sigma_{\mathrm{r}}=178.6 \mathrm{kPa}$.

Settlement $\Delta \mathrm{H}=\frac{\Sigma \mathrm{H}_{0}}{1+\mathrm{e}_{\mathrm{o}}} \Delta \mathrm{e}$

or

$\frac{10 \mathrm{~m}}{1.83}(0.06546)=0.36 \mathrm{~m}$.

(This example is based on actual values measured in Los Alamos, New Mexico, using crushed tuff, which has the texture of a sandy silt and whose actual geotechnical characteristics are the ones used in the preceding example.) 
Also since

$\frac{\Delta \mathrm{e}}{1+\mathrm{e}}=\mathrm{m}_{\mathrm{v}} \sigma$

$\Delta \mathrm{H}=\Sigma \mathrm{H}_{\mathrm{o}} \overline{\mathrm{m}}_{\mathrm{v}} \Delta \sigma$

or

$10 \mathrm{~m} \times 26 \cdot 10^{-8} \mathrm{~Pa}^{-1} \times 1.1 \cdot 10^{5} \mathrm{Fa}=0.29 \mathrm{~m}$.

or since $a_{v}=(1+e) m_{v}$

$\Delta \mathrm{H}=\frac{\Sigma \mathrm{H}_{\mathrm{o}}}{1+\mathrm{e}_{\mathrm{o}}} \overline{\mathrm{a}}_{\mathrm{v}} \Delta \sigma$

or

$\frac{10 \mathrm{~m}}{1+0.83} 45 \cdot 10^{-8} \mathrm{~Pa}^{-i} \times 1.1 \cdot 10^{5} \mathrm{~Pa}=0.27 \mathrm{~m}$.

If computed according to the method proposed by Holtz and Kovacs (1981):

since $\Delta \mathrm{e}=-\mathrm{C}_{\mathrm{c}} \log \frac{\sigma}{\sigma_{\mathrm{o}}}$

$\Delta \mathrm{H}=\frac{\Sigma \mathrm{H}_{\mathrm{o}}}{1+\mathrm{e}_{\mathrm{o}}} \mathrm{C}_{\mathrm{c}} \log \frac{\sigma_{\mathrm{f}}}{\sigma}$

or

$\frac{10 \mathrm{~m}}{1+0.83} \times 0.14635 \log \frac{178.6 \mathrm{kPa}}{68.6 \mathrm{kPa}}=0.33 \mathrm{~m}$.

The four methods yield $\bar{x}=0.31 \mathrm{~m}$ and $\mathrm{s}=0.04 \mathrm{~m}$. This indicates a remarkable agreement between the different methods applied. This is even more true if one considers the fact that the average volume compressibility $\bar{m}_{v}$ and the average coefficient of compressibility $\bar{a}_{v}$ were calculated from the $m_{v}$ and $a_{v}$ values at $\tau=120 \mathrm{kPa}$, and $250 \mathrm{kPa}$ found in "Geotechnical Aspects of Hackroy Sandy Loam and Crushed Tuff" (Abeele 1984). Since the curves are not linear, $a_{\mathrm{v}}$ varies widely over large pressure ranges and makes the agreement that more notable. The stress was computed for mid-depth because the average initial effective stress is identical to the initial stress at mid-depth (stress increases directly proportional to depth).

A refined Holtz method will be described later. That method is handled as if the profile consists of several different compressible strata. The total settlement is then eoual to the sum of settlements for each compressible stratum or $\Delta \mathrm{H}_{\mathrm{tol}}=\Delta \mathrm{H}_{1}+\Delta \mathrm{H}_{2}+\Delta \mathrm{H}_{3}+\ldots$ No shortcut should be made by averaging estimated individual stratum settlement because each is likely to possess a very proper and different coefficient of consolidation; therefore, each stratum must be analyzed individually.

Sowers (1979) indicuies also that analyses performed by Schmertmann show that $90 \%$ of the distortion settlement in sandy soils occurs within a depth of twice the width, B, of the loaded area, 
which in the case of a waste disposal site, could be quite deep. Deeper than 2B, there is very little settlement from any surface lcad because $E$, the elasticity modulus, increases with depth and confinement, whereas the effects of any surface load decrease rapidly with depth.

Compressio. of sandy soils is rareiy observed because consolidation is immediate but occurs gradually during each loading.

Safety factors required for computation of settlement design depend on how accurately the soil condition and the nature and compaction state of the waste are known and how critical a settlement failure would be. The permissible amount of settlement depends on soil uniforinity and subsequent settlement and the dimension of the waste site and the safety factor could vary accordingly between 1.5 and 4 . To compare settling behavior in a material with much slower consolidation, we mixed our sandy silt (crushed tuff) with $4 \%$ bentonite and predicted a settlement of $10 \mathrm{~m}$ of such a saturated mix provided the same material as in the previous case was used as backfill ( $8 \mathrm{~m}$ of backfill having a uni1 weight of $13.7 \mathrm{kN} \mathrm{m}^{-3}$ ).

Properties of the slightly preconsolidated bentonite/sandy silt mix are:

Initial void ratio: $\mathrm{e}_{\mathrm{o}}=0.757$;

Compression index: $C_{c}=0.145$;

Coefficient of consolidation: $4.16 \times 10^{-7} \mathrm{~m}^{2} \mathrm{~s}^{-1}$;

Uni1 weight: $16 \mathrm{kN} \mathrm{m}^{-3}$.

The water table is well below the area io be considered.

1. Initial effective stresses are first computed

a. at $0 \mathrm{~m}: \sigma_{(0)}=0$

b. at $-5 \mathrm{m:} \sigma_{(-5)}=16 \mathrm{kN} \mathrm{m}^{-3} \times 5 \mathrm{~m}=80 \mathrm{kPa}$

c. at $-10 \mathrm{~m}: \sigma_{(-10)}=16 \mathrm{kN} \mathrm{m}^{-3} \times 10 \mathrm{~m}=160 \mathrm{kPa}$

2. Stress increase due to backfill

$\Delta \sigma=13.7 \mathrm{kN} \mathrm{m}^{-3} \times 8 \mathrm{~m}=109.6 \mathrm{kPa}$

3. Final effective stress, $\sigma^{\prime}$

a. at $0 \mathrm{~m}:=109.6 \mathrm{kPa}$

b. at $-5 \mathrm{~m}:=189.6 \mathrm{kPa}$

c. at $-10 \mathrm{~m}:=269.6 \mathrm{kPa}$

4. If we assume one-dimensional consolidation and a one-time load application, then settlement $\Delta \mathrm{H}$ yields $[\mathrm{Eq}(26)]$ :

$\Delta H=\frac{\Sigma H_{0}}{1+\mathrm{e}_{0}} C_{\mathrm{c}} \log \frac{\sigma^{\prime}{ }_{(-5)}}{\sigma_{1-5)}}=\frac{10 \mathrm{~m}}{1+0.757} \times 0.145 \log \frac{189.6 \mathrm{kPa}}{80 \mathrm{kPa}}=0.31 \mathrm{~m}$

If, however, the total thickness of the layer under pressure is divided into thinner layers, the accuracy of the results will be improved. The settlement of each layer is then summed to obtain the total consolidatior thement. A settlement computation (Table XVIII) can be used. Suppose we 
divided each layer in thicknesses of $1 \mathrm{~m}$ each. The mid-depths are then, respectively, at $\mathrm{d}$ (in meters) with corresponding values of $\sigma, \sigma^{\prime}, \sigma^{\prime} / \sigma, \log \sigma^{\prime} / \sigma$, and

$\frac{\Sigma H_{o}}{1+c_{1}} C_{c}=0.0825$ (constant)

In this case, $\Sigma \Delta \mathrm{H}=0.40 \mathrm{~m}$, which is a more accurate result. We see that the settlement estimate increased by $29 \%$ using the method improved by Holtz. The total consolidation for a $4 \%$ bentonite/sandy silt mix would consequently be $4 \%$ according to Holtz. It is generally agreed that consolidation settlements can only be predicted within a range of $20 \%$ (Holtz and Kovacs 1981).

To compute the time rate of settlement, we need the relationship between the percentage consolidation, $U$, and a "time factor," $T_{v}$. This was derived mathematically by Terzaghi. If we consider the bentonite/sandy silt to have single drainage, the value $\mathrm{H}_{\mathrm{dr}}$ (thickness of soil under stess/drainage outlets) is equal to $10 \mathrm{~m}$. The coefficient of consolidation approximates 1 $\mathrm{m}^{2} /$ month. Based on the above, we can construct Table XIX.

We can see that the consolidation, which has been found to be almost instantaneous in sandy silt, has increased noticeably with the addition of only $4 \%$ by weight of bentonite.

\section{Subsidence}

The distinction be:ween subsidence and settlement is not always apparent. For those who make that distinction, subsidence is a vertical earth movement that, rapid or slow, can take on catastrophic proportions. Slow subsidence is caused by reducing the neutral stress and increasing the effective stress, by pumping of wa $-\tilde{r}$ or oil and causing some kind of passive consolidation. This, in turn, causes the ground surface to sink selectively.

Rapid subsidence occurs in mining areas where cavities produced by cave-ins gradually or sometimes abruptly reach the surface. The soil layer bridging the cavity then collapses and slides vertically downward. Disintegration of waste materials in shallow land burials can have the same effect.

\section{TABLE XVIII}

\section{SETTLEMENT COMPUTATIONS}

\begin{tabular}{|c|c|c|c|c|c|}
\hline$d(m)^{a}$ & $\sigma(\mathbf{k P a})^{\mathbf{b}}$ & $\sigma^{\prime}(\mathbf{k P a})^{c}$ & $\sigma^{\prime} / \sigma$ & $\log \sigma^{\prime} / \sigma$ & $\Delta \mathbf{H}(\mathbf{m})^{\mathrm{d}}$ \\
\hline 0.05 & 8 & 117.6 & 14.700 & 1.167 & 0.096 \\
\hline 1.5 & 24 & 133.6 & 5.567 & 0.746 & 0.062 \\
\hline 2.5 & 40 & 149.6 & 3.740 & 0.573 & 0.047 \\
\hline 3.5 & 56 & 165.6 & 2.957 & 0.471 & 0.039 \\
\hline 4.5 & 72 & 181.6 & 2.522 & 0.402 & 0.033 \\
\hline 5.5 & 88 & 197.6 & 2.245 & 0.351 & 0.029 \\
\hline 6.5 & 104 & 213.6 & 2.054 & 0.313 & 0.026 \\
\hline 7.5 & 120 & 229.6 & 1.913 & 0.282 & 0.023 \\
\hline 8.5 & 136 & 245.6 & 1.806 & 0.257 & 0.021 \\
\hline 9.5 & 152 & 261.6 & 1.721 & 0.236 & 0.019 \\
\hline
\end{tabular}


TABLE XIX

TIME RATE OF SETTLEMENT

\begin{tabular}{|c|c|c|c|}
\hline $\mathbf{U}$ & $T_{v}$ & $\Delta \mathbf{H}(\mathbf{m})$ & t(months) \\
\hline 0.1 & 0.008 & 0.04 & 0.8 \\
\hline 0.2 & 0.031 & 0.08 & 3 \\
\hline 0.3 & 0.071 & 0.12 & 7 \\
\hline 0.4 & 0.126 & 0.16 & 13 \\
\hline 0.5 & 0.196 & 0.20 & 20 \\
\hline 0.6 & 0.286 & 0.24 & 29 \\
\hline 0.7 & 0.403 & 0.28 & 40 \\
\hline 0.8 & 0.567 & 0.32 & 57 \\
\hline 0.9 & 0.848 & 0.36 & 85 \\
\hline 0.95 & 1.129 & 0.38 & 113 \\
\hline 1.00 & $\propto$ & 0.40 & $x$ \\
\hline
\end{tabular}

Bracing of any excavation is required to prevent the phenomenon known as "lost ground" (Sowers 1979), which occurs when surrounding soil is being squeezed into newly-formed excavations. This is usually noticed when the excavated volume of soil exceeds the volume of the excavation when finished. This will lead to subsidence of areas immediately surrounding excavated waste pits. Such events are particularly troublesome in soft clays and can be remedied only by careful bracing.

\section{REMEDIAL ACTION}

Settlement can be prevented or at least curtailed by building earth embankments on top of unconsolidated scils before the final structure is to be emplaced. Building arid subsequent removal of such embankments, which will have a reduction of void ratio as a result, is termed preloading. If, as in the casi of a waste pit, the lateral extent of the preload is large in comparison to the thickness of compressible waste, one-dimensional strain computations may be adopted. Preloading may be considered attractive only if the compressible material (for example, crushed tuff + waste products) drains rapidly if saturated, so that preloading ...ne is relatively short. To obtain this, relatively thin layers with low coefficient of consolidation will have to prevail or thick layers with a high coefficient of consolidation will qualify. In other words, if the coefficient of consolidation is iow, the drainage path should be short. A higher load or surcharge will of course shorten the consolidation time and the pit contents will be compressed to a higher effective stress.

A second way to obtain settlement curtailment is through soil stabilization. Soil stabilization means the improvement of a soil property so as to remediate on its geotechnical performance. This may be intended to increase the elasticity modulus, which in turn may imply an increased strength or decreased comprissibility or both, or it may portend decreased permeability. Soil improvement may be temporary in intent or permanent. Lambe and Whitman (1979) classify soil improvement techniques according to the process entailed, material addition, or intended result. Based on the process involved, stabilization can be induced mechanically, chemically, electrically, or thermally and each of these can be accomplished in several ways. Densification of soils or void ratio reduction is most commonly obtained through static and dynamic (also vibratory) compaction.

Densification by means of rollers is best for the upper layers of a subgrade, sand (which can be densified with rollers to 1 or $2 \mathrm{~m}$ depth), or freshly placed soil layers. 
Granular soils can also be effectively densified using vibratory rollers. A $60 \mathrm{kN}$ roller operating at a frequency of $27.5 \mathrm{~Hz}$ results in the most efficiı:nt compaction around a $0.6-\mathrm{m}$ depth, which is the geatest depth at which zero effective stress occurs during rebound under abovedescribed circumstances (see Fig. 8, adapted from D'Appolonia et al. 1968) Densification depth wiii increase somewhat with the number of passes (see Fig. 9, adapted from D'Appolonia et al. 1968).

Another form of dynamic consolidation is achieved by dropping heavy steel masses (up to 40 tons) from heights of up to $40 \mathrm{~m}$. This method, developed in Europe, was proven effective to depihs of $20 \mathrm{~m}$ with settlements amounting to $15 \%$ of the total compacted backfill thickness. The 40-ton mass is lifted by crane and dropped according to a predetermined pattern for the entire site. This nethod, however, could lead to the collapse of waste containers and the nefarious effects related to such events range from release of radioactive gas to exposure to percolating water. To avoid this. the drop height should be selected so that the effectivenes: of the compactive effort does not extend beyond the backfill. Such impact force would be sufficient to collapse soil bridges over voids between containers (Kahle and Rowlands 1981).

Pile driving is aimed at the densification of cohesionless soils. In this case, densification is produced by displacement of material equal to the buried pile and by accompanying vibratory effects.

In cohesive soils, preloading (or surcharging), or the use of rubber-tired rollers with tire pressures up to $1 \mathrm{MPa}$ is usually the most effective (static loads!). The extrusion of a viscous cement/sandy loam mix into the soil voids can lead to a form of compaction (or reduction of void ratio) known as grouting. In situ soil compaction occurs through radial compression.

Figure 10 is a representative model of the manner in which dry unit weight of sand changes as a function of applied acceleration in a laboratory vibration study (adapted from D'Appolonia et al. 1968). Peak density was obtained at $2 \mathrm{~g}$ acceleration, with sand being most sensitive at acceleration changes around $1 \mathrm{~g}$. The densification process seemed to be independent of the vibration

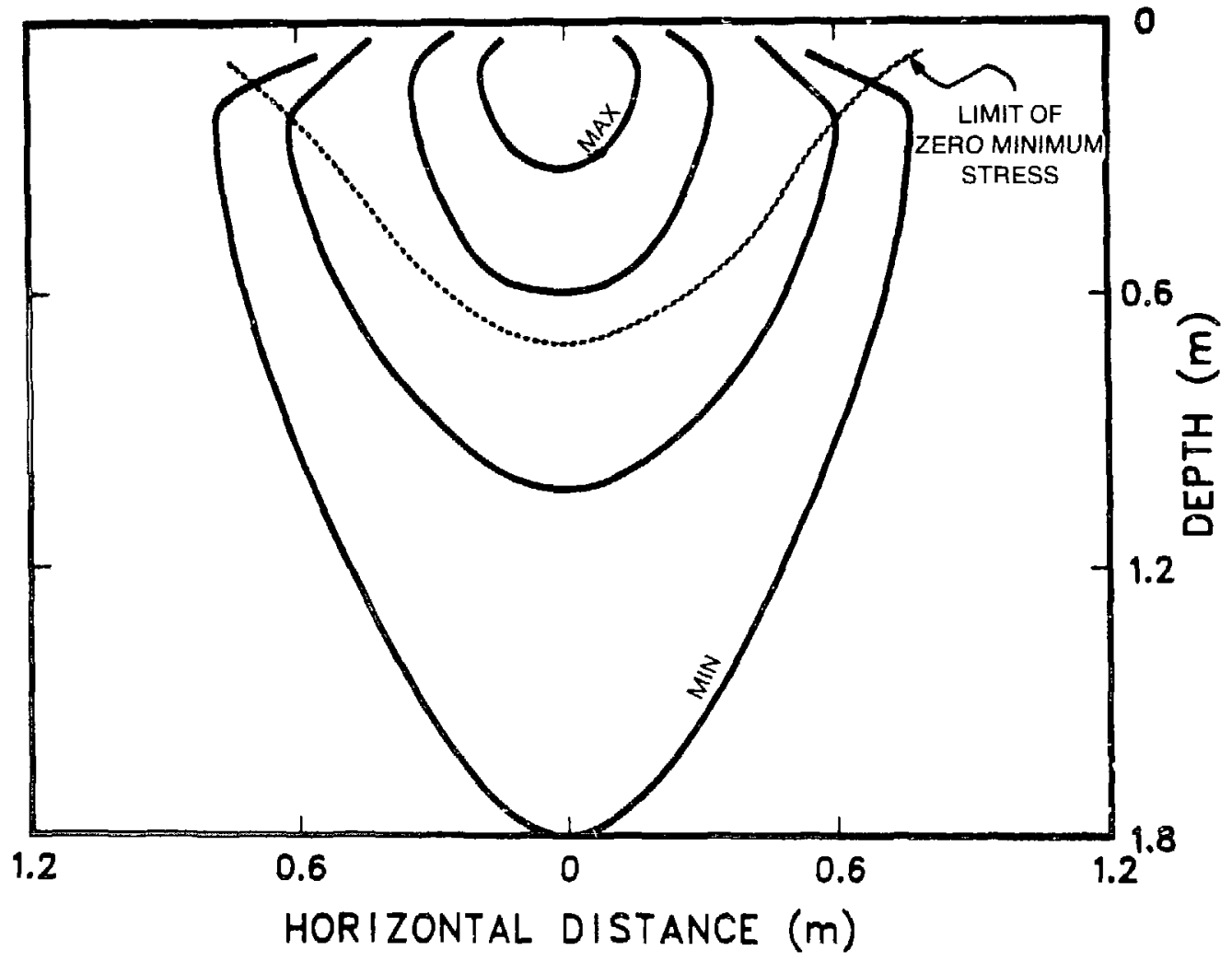

Fig. 8. Contours of maximum vertical dynamic stress beneath vibratory roller. 


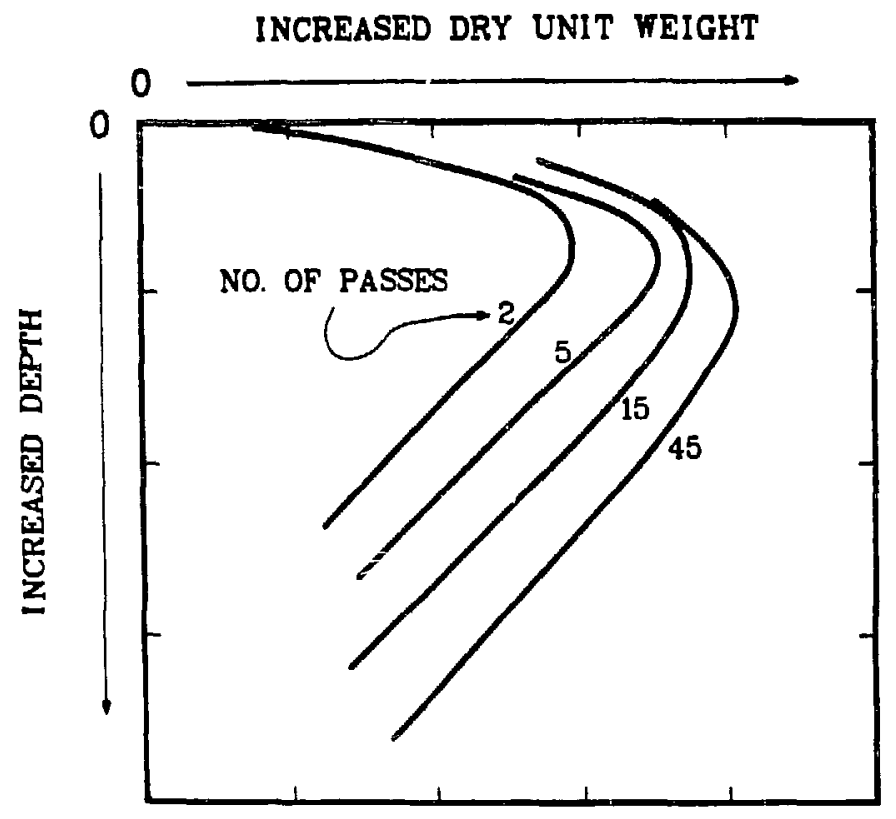

Fig. 9. Densification by vibratory roller.

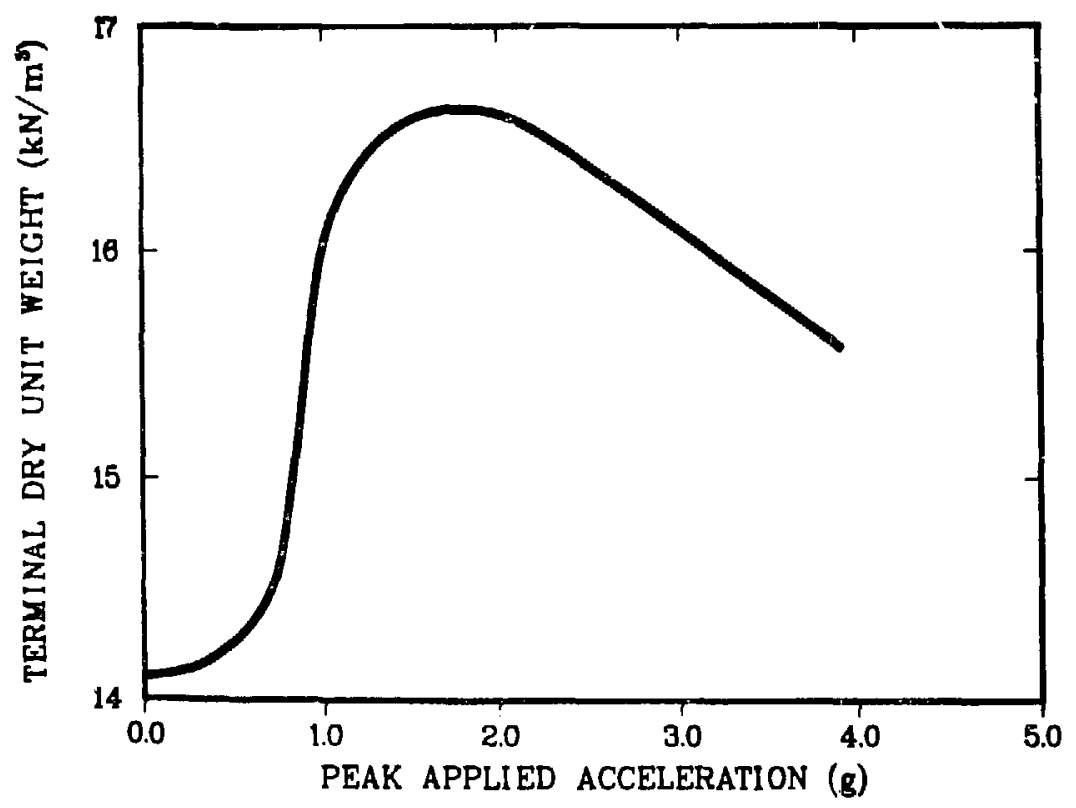

Fig. 10. Representative model obtained in laboratory vibration study. 
amplitude. A purely static load does little to densify sand unless tie stress is high enough to crush the sand granules. Consequently. something specific to a vibratory motion must be at the origin of sand densification. It has been proposed that at the point in each vibrational cycle where the downward acceleration of the vibrating table reaches $1 \mathrm{~g}$ or more, the vertical (static) stress within the soil is zero. Because sand is a porous, loose material that cannot bear tension, it is unable to follow the motion to which the vibrating table is submitted and undergoes free fall until mutual impact of the sand granules occurs once the motion reverses direction. Free-fall is what seems to characterize densification since it is only worthwhile at accelerations equal to or greaiter than $1 \mathrm{~g}$. It is as if the absence of stress allows the particles to break physical contact and be driven into position of optimum density as the vibrating mass reverses direction. The absence of a stress period seems tu be essential to the densification process.

\section{Compaction Testing}

The most prevalent compaction test is the dynamic compaction test, consisting of dropping a hammer of specified mass a given number of times from a particular height on the soil to be 1 :sted. If a soil is compacted according to constant values for mass, height and number of blows, and variable water contents, then plotting of moisture content vs dry density will show that an optimum value of dry density can be attained as a function of water content (water content will cause the dry density to increase to a peak and subsequently decrease). We see in Fig. 11 that a maximum dry density of $1.83\left(17.85 \mathrm{kN} \mathrm{m}^{-3}\right.$ unit weight $)$ is reached at an optimum moisture content of $13 \%$ for a bentonite/sandy silt ratio of 0.02 .

Figure 12 shows clearly that by decreasing the compactive effort, the maximum dry density lowers in value and the optimum water content increases (Lutton et al. 1979). Also, as the moisture content increases, the cause and effect relationship between compactive effort and dry density tends to decrease. The line connecting the points of maximum dry density (or optimum water content) seems to run more or less parallel to the saturation line $(s=100 \%)$. It is immediately obvious from this graph that the saturation ratio decreases with decreasing dry unit weight if the water content by mass remains the same. This only shows that a lower dry unit weight corresponds to a higher void ratio or porosity.

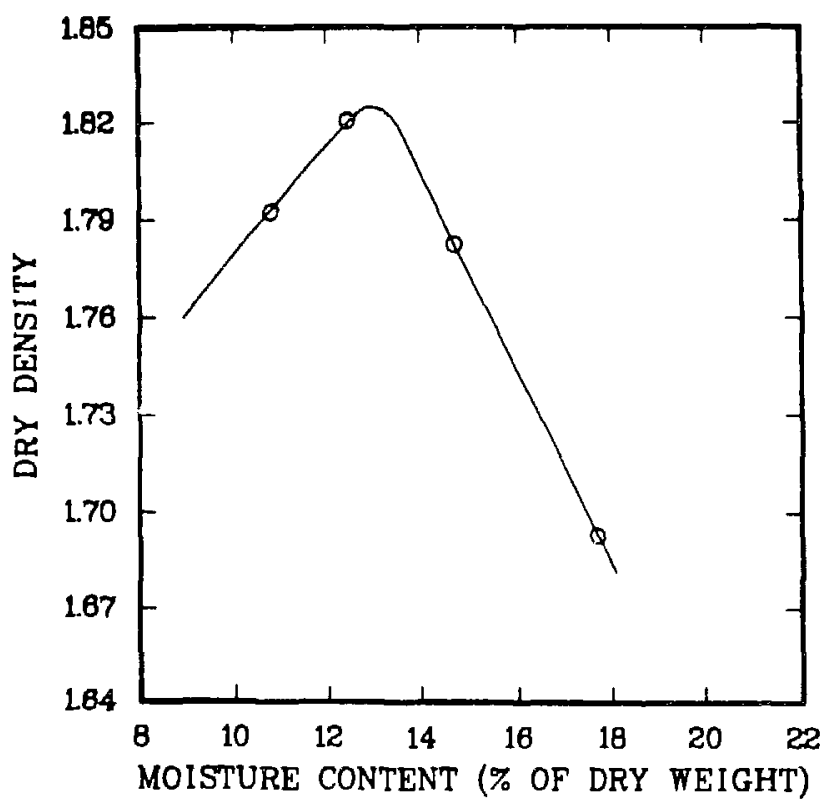

Fig. 11. Compaction test. 


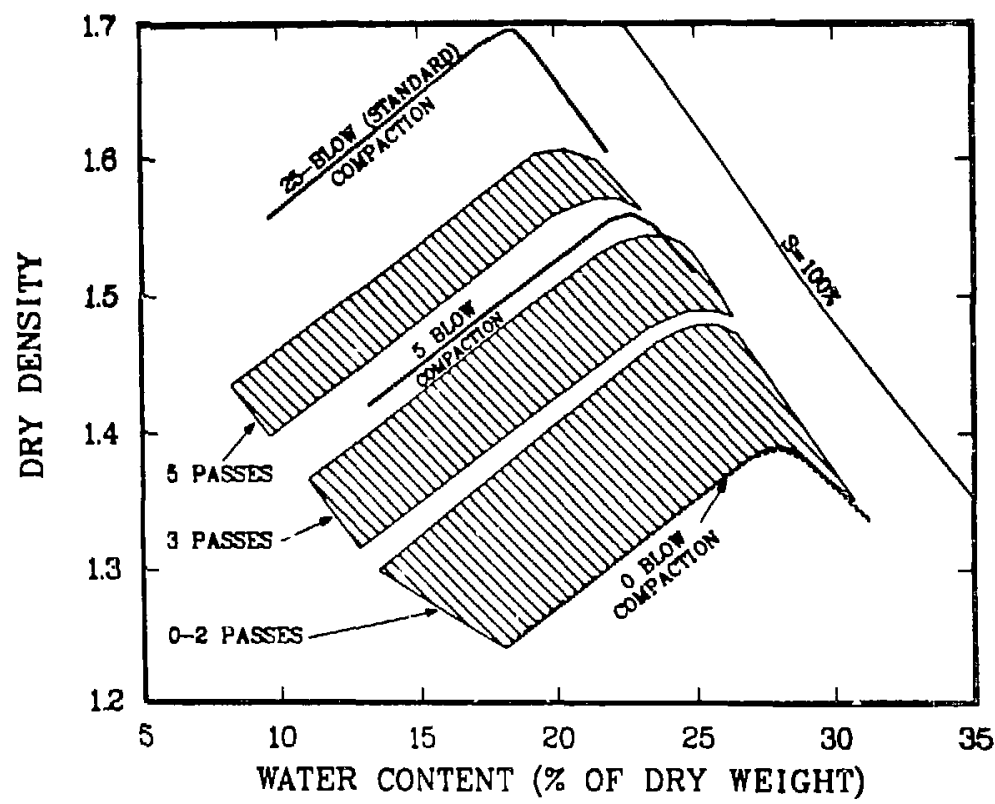

Fig. 12. Dry density as a function of water content.

The srease in void ratio can also have drastic consequences on the hydraulic conductivity, as formerly depicted in Fig. 6 where void ratio is plotted against hydraulic conductivity for different bentonite ratios. Lutton et al. (1979) show the same effect taking place on different materials (Fig. 13). They aiso show the effect of void ratio on the angle of internal friction where it is clearly shown that. for any particular soil, a decrease in void ratio inevitably leads to soil stabilization because of a higher angle of internal friction (Fig. 14). It should be kept in mind that bollı a soil strength increase and a reduced permeability resulting from one form or another of compaction affect ine integrity of a waste pit cover pusitively.

Although soils compacted over waste pits are generally relatively soft, one should strive for, on a granular soil-like sulid waste, $90 \%$ of maximum dry density obtained by the 25 -blow standard compaction test. Figure 1 ( ) (Lutton et al. 1979) shows how compaction curves vary with various soil types. S. Phillips (1983) shows that, by mixing styrofoam in a ratio of $1: 1$ to silty sand, the coefficient of compressibility, $\mathrm{a}_{\mathrm{w}}$, which varied from $1.88 \times 10^{-7} \mathrm{~Pa}^{-1}$ to $1.04 \times 10^{-7} \mathrm{~Pa}^{-1}$ for corresponding stress intervals of 0 to $239 \mathrm{kPa}$ and 239 to $575 \mathrm{kPa}$ for silty sand, adopted values varying from $1.52 \times 10^{-6} \mathrm{~Pa}^{-1}$ to $2.17 \times 10^{-6} \mathrm{~Pa}^{-1}$ for the mix. Thus, he concludes that a one order of magnitude change in $\mathrm{a}_{\mathrm{v}}$ is realized as the composition is changed to $50 \%$ highly compactible material. The compression index $\mathrm{C}_{\mathrm{c}}$ also changed by one order of magnitude.

Lowering of the water table or dewatering is probably the best known cause of massive settlement. When submerged, soil particles are subjected to buoyancy. Upon dewatering, the buoyancy is removed and the apparent increase in pressure results in consolidation, even though there is no increase in external load. In the case of crushed tuff, the ratio of dry tuff density $(\gamma d)$ and submerged tuff $(\gamma s)$ is equal to:

$\gamma \mathrm{d} / \gamma_{S}=\frac{(1-n) G \gamma_{w}}{(1-n)(G-1) \gamma_{\mu}}$

or

$\frac{1.54}{0.94}=1.64$ 


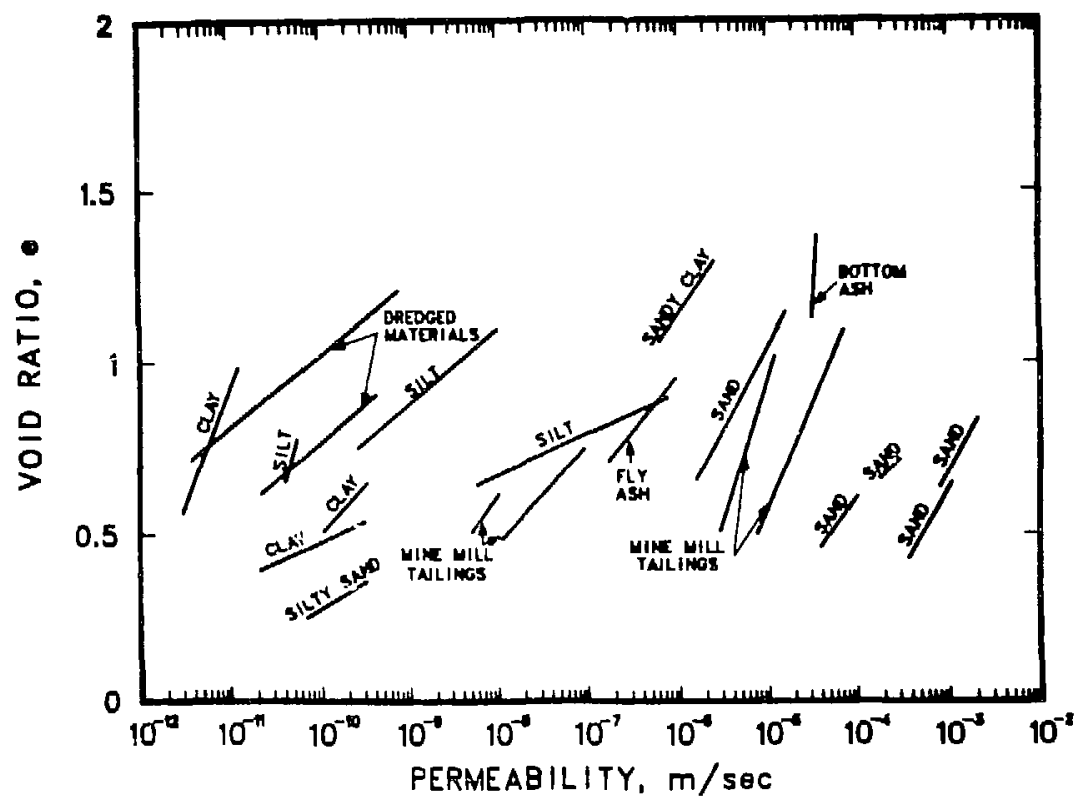

Fig. 13. Permeability of materials as affected by void ratio.

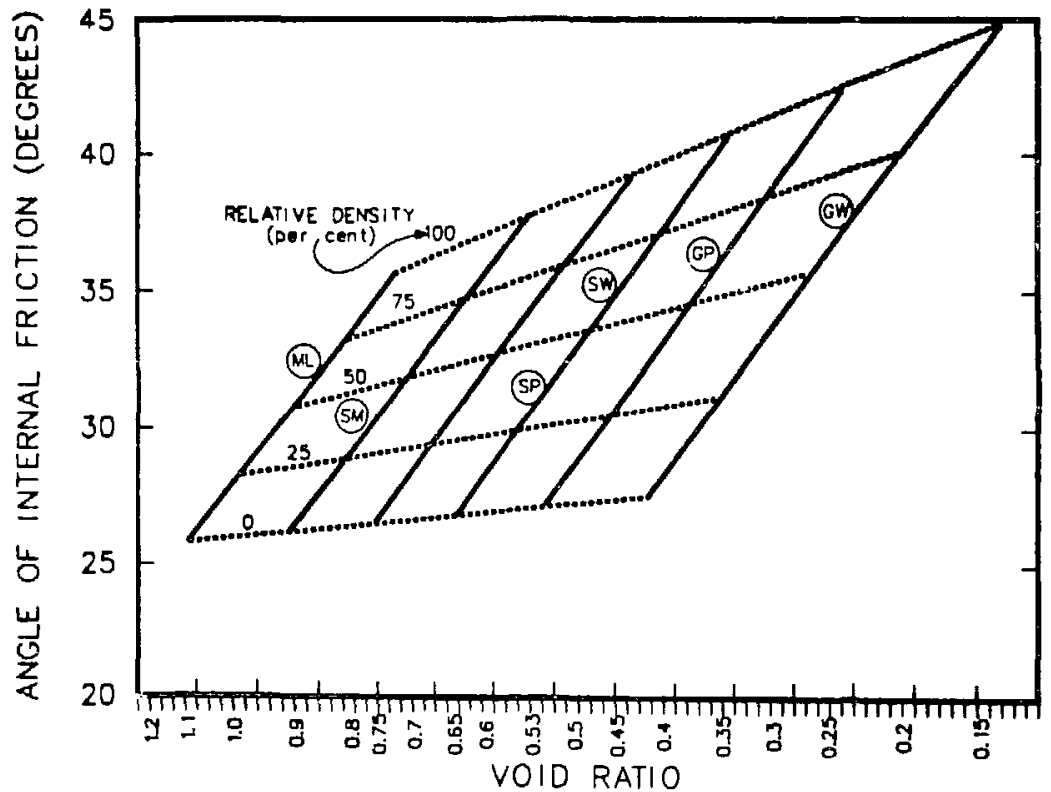

Fig. 14. Relation of effective angle of internal friction to void ratio for various soil types. 


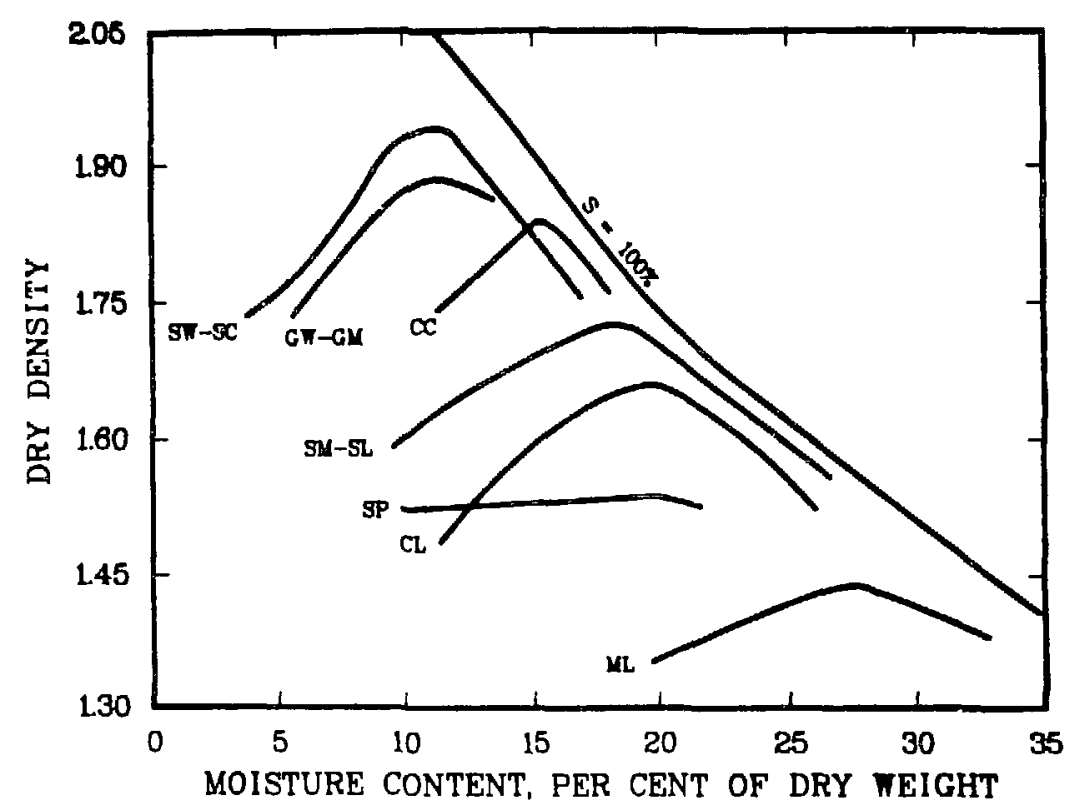

Fig. 15. Compaction curves for various soil types.

where $\mathrm{n}=$ porosity $=0.40$ under static load of $250 \mathrm{kPa} ; \mathrm{G}=$ specific density of tuff particles $=2.56$; $\gamma_{u}=$ density of water $=1$; and $\gamma \mathrm{d} / \gamma \mathrm{s}=1.64$ means that the unit weight of crushed tuff is approximately 1.6 times higher when dry than when submerged. This ratio is valid for most soils and is the main reason for the consolidation and subsequent subsidence of Mexico City, where the rate of pumping causes the city to settle at a rate close to $2 \mathrm{~mm}$ per day. High pumping rates and the thickness of ine bentonite layer. which is known to have a void ratio as high as 15 , and massive monuments and skyscrapers are the cause of the literal "disappearance" of the city. The volcanic ash. at the origin of the bentonitic clay, has a unit weight averaging only $6 \mathrm{kN} \mathrm{m}{ }^{-3}$, and consequently, is very compressible when loaded (as by dewatering).

If dewatering is desired, i.e., means other than mechanical (pumping) can be used for the construction and maintenance of a waste pit; they are use of drains and electro-osmosis.

Vertical drains can consist of sand or geotextiles and are generally used in conjunction with preloading to accelerate clay consoliciation.

\section{FIELD SUBSIDENCE EXPERIMENT}

\section{A. Test Plan}

Subsidence cavities measured on actual burial trenches vary widely in both size and shape, from broad, shallow depressions to narrow pipes that may extend to the waste. Burial site surveys indicate that about $85 \%$ of the measured cavities are less than $2.75 \mathrm{~m}$ in diameter and $95 \%$ are less than $4.25 \mathrm{~m}$ in diameter.

To stress the biobarrier, cavities of four sizes were created. There are two replicates of each and two control plots. The experiments are conducted in a trench 38-m long, 15-m wide, and 3-m deep. In the boltom of each $58-\mathrm{m}^{2}$ experimental plot we augered a $0.9-\mathrm{m}$ diameter hole to a depth necessary to equal the desired volume of the subsided cavity (1.4-, 3.4-, 6.4-, and 11.5-m deep). Over each of these drawholes was a $2.25-\mathrm{m}^{2}$ steel plate with a hinged trap door, which was fastened by explosive closures. One side of the drawholes was cut away flat to a depth of $1-m$ to allow the door to open fully. The entire trench was backfilled to a depth of $2.2-\mathrm{m}$ with crushed tuff, screened 
to remove particles larger than $5-\mathrm{cm}$ to prevent clogging. The backfill is overlain by $0.9-\mathrm{m}$ of cobble/gravel biobarrier material and soil. A layer of cesium-chloride tracer was placed at the backfill/barrier interface. Alfalfa was planted uniformly on the surface.

When the explosive closures were released, the trap doors fell downward, allowing the backfill to drain into the drawholes, causing subsidence at the surface. Slow subsidence of the entire trench surface, resulting from continued stabilization of the backfill, should be observable throughout the duration of the experiment.

Plant root penetration is being monitored by routine sampling of plant leaves. Cesium concentrations in the leaves will be mapped as a function of time and location relative to the subsided cavities. Root penetration (if any) can be expected to occur first at the cavity rims-regions of maximum tensile stress and elongation.

At the end of the experiments, the plots will be excavated to measure the actual degree of root penetration through the barrier. At the same time, both the upper and lower surfaces of the bicuarrier will be mapped to determine the physical effects of subsidence on the barrier and to correlate with the tracer data and root measurements.

\section{B. Preliminary Results}

The resistance to subsidence should be equal above all eight drawholes since the main parameters influencing subsidence are unchanged in the backfill overlying the eight drawholes. The uniform backfill thickness-drawhole diameter ratio (t/d)-was high eñough to prevent subsidence at any of the eight locations. We were even told by the explosives experts that two of the explosive bolts might not have detonated. For some time it looked as if subsidence would occur by accident (as it eventually does in a completely natural environment) or some method had to be found to induce or enhance subsidence without using disruptive mechanical means, which would leave a permanent imprint of "artificial" intervention.

From this exreriment it is obvious that the crushed tuff and/or the soil have some cohesiveness, as was demonstrated in the laboratory (Abeele 1984). The lab results also show that, even for crushed tuff, a 'igher degree of consolidation or compression is at the origin of an increase in soil strength. (1t is well known that densification causes soil stabilization). The bottom of the landfill. which is submitted to a pressure averaging $50 \mathrm{kPa}$. could consequently be fairly well stabilized when dry.

A completely cohesionless porous medium (Ottawa sand. for example) would have undergone immediate subsidence into the $0.9 \mathrm{~m}$ diameter drawholes when the trapdoors were released. This was obviously not observed when the trapdoors. overlain by crushed tuff, were opened.

As stated earlier, the presence of excess water reduces the effective stress responsiole for the friction between solids. Therefore, it was decided that by increasing the water content of the backfilling, the shear strength may decrease enough to cause failure or subsidence, while preserving the "natural" setup. This action could in no way be considered to be totally undisturbing to the environment because it was suspected that the amount of water reeded would far exceed the amount of water available through natural precipitation in Los Alamos.

Flooding of the area immediately overlying the drawholes caused subsidence in two 1.4-m deep holes, two 3.4-m deep holes, two 6.4-m deep holes. and one 11.5 -m deep hole. This is one hole more than was thought possible because it was speculated that two trapdoors had failed to open.

The shape of the subsidence holes is far from resembling an inverse cone with regular slope. Instead, it has, in most cases, a vertical wall where the cohesive materials are located (the Hackroy series soil), and extremely irregular angles where the diameter of the unstable moving materia! is not small compared with the height of the slope (gravel and cobble in our case). The ratio of the diameter of the unstable moving material to the total slope has to be small to satisfy the demand for identification of the angle of repose, which represents the angle of internal friction and/or maximum slope angle of a granular material at its loosest state. The ratio diameter/length of the slope is too high in the case of gravel and cobble and the compression is too high in the crushed tuff for their slope angle to be representative of the angle of repose. Cohesion prevents the Hackroy serier, soil from adopting an angle that is indicative of what the angle of repose might be. 
The total volume of the subsided cavities seems to relate pretty well as $1: 2.5: 8 . j$ or roughly the relationship existing in the size of the respective drawholes. The volume of the cones is extremely difficult to compute for the two smaller ones but averages arcund $90-95 \%$ of the drawhole volume for the remaining five. These results are justifiable because pores created by rocks filling the drawholes will be at the origi in of a lower bulk density in the drawhole and will correspond to a smaller conic volume at the surface.

Principles based on relationships between surface deformation and underground cavities can be applied to predict fundamental quantities such as maximum possible subsidence. Generalization of these empirical relationships can lead to calculation of complete deformation profiles, provided:

1. The stratification is horizontal (soil, biobarrier, tuff).

2. The subsidence reached its final stage.

3. The cavities are geometrically simple.

Because the above conditions are fulfilled, final deformation is characterized by the foilowing facts:

1. The surface subsidence boundaries extend beyond the horizontal edges of the cavity.

2. Concurrent with subsidence, horizontal displacements producing stresses occur, whose magnitude depends on the subsidence slope. Those movements are larger than would be expected from the subsidence curvature.

3. The cylindrical nature of the cavity causes maximum subsidence over the center, where there is no horizontal movement. w'itereas the vertical and horizontal stresses and subsequent displacements should be symmetrically distributed over the subsidence area.

The vertical component, whose upper limit is defined as "maximum possible subsidence" is only present if the cavity has a minimum "critical area."

ln case a critical area is present, the central maximum possible subsidence is coupled with zeio curvature and strain (Fig. 16). Prediction of maximum subsidence is based on the fact that it is correlated to cavity thickness, or $S=$ at [Eq (29)] where $a=$ subsidence factor. If the displacements caused by any cavitv on our plot are affected by displacements caused by neighboring cavities, then we would witness a superiposition of surface displacements. Since this was not the case, we can assunic that every cavity was unaffected (through distance) by the presence of any other.

Maximum subsidence is also dependent on the subsidence factor, which in turn depends on the depth of the cavity, its lateral dimensions, and stability of overlying soil layers. $\mathrm{L}$ rause these three parameters are the same for all cavities, the only variable remaining in our plot is $t$. The subsidence factor would be very difficult to determir.e for our heterogeneous overburden, but one would expect it to decrease with increasing depth. The General Institute of Mining Surveying (1958) suggests:

$\mathrm{S}=\frac{25 \mathrm{~m}}{25+\sqrt{\mathrm{h}}} \cos \alpha$

where $\alpha=$ angle of dip

$\mathrm{h}=$ depth of cavity.

This formula does indeed point to a decrease of subsidence with depth.

The National Coal Board, Mining Department (London 1975) tried to predict maximum subsidence basr. 1 on curves em: pirically derived from actual measured occurrences, which appear under certain conditions. However, those curves are not drawn for cavities of less than $10-\mathrm{m}$ in diameter, W, or at depths, $h$, of less than $50-\mathrm{m}$. Since the $\mathrm{W} / \mathrm{h}$ ratio is important for the use of these curves (named S/m curves), I wondered what would happen if I multiplied $\mathrm{W}$ and $\mathbf{h}$ with constant factors to see what $\mathrm{S} / \mathrm{m}$ ratio (Table $\mathrm{XX}$ ) could be read on the curve used to compute subsidence based on the width and depth relationship. (In our case, $\mathrm{W}=0.90 \mathrm{~m}$ and $\mathrm{h}=3.1 \mathrm{~m}$.) 


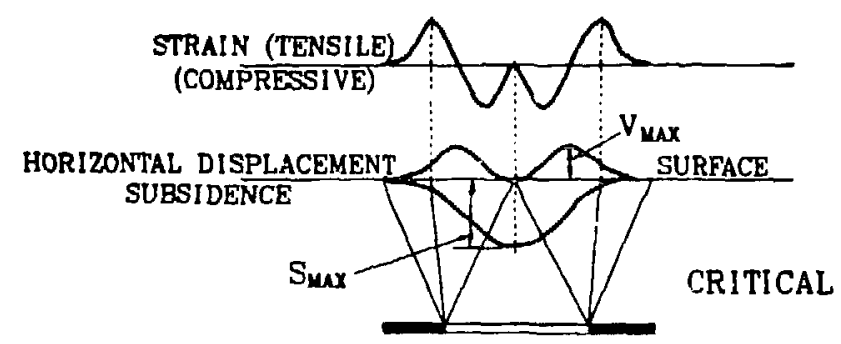

Fig. 16. Subsidence and slirface movements (Brauner 1973).

\section{TABLE XX}

\begin{tabular}{|c|c|c|c|}
\hline \multicolumn{4}{|c|}{$\begin{array}{c}\text { RELATIONSHIP OF SUBSIDENCE TO } \\
\text { WIDTH (W) AND DEPTH }(\mathrm{k})\end{array}$} \\
\hline$W^{\prime}(\mathbf{m})$ & $k(m)$ & $\mathbf{W} / \mathbf{k}$ & $\mathrm{S} / \mathrm{m}$ \\
\hline 90 & 310 & 0.29 & 0.18 \\
\hline 135 & 465 & 0.29 & 0.22 \\
\hline 180 & 620 & 0.29 & 0.20 \\
\hline 225 & 775 & 0.29 & 0.19 \\
\hline 270 & 930 & 0.29 & u. 22 \\
\hline
\end{tabular}

If we lake the averaged obtained $S / m$ value $(0.2)$ and extrapolate to a depth of $3.1 \mathrm{~m}$, then we find (Table XXI) that for cavities of thickness. 1. the preslicted vs measured subsidence agree reasonably well.

As we can see, even though this method may seem uñorthodox, the deepest and the most shallow cavities show the highest proportional deviations.

TABLE XXI

PREDICTED ( $\left.S_{p}\right)$ VS MEASURED

SUBSIDENCE $\left(S_{m}\right)$

\begin{tabular}{|c|c|c|}
\hline$t(m)$ & $S_{p}(m)$ & $S_{m}(m)$ \\
\hline 1.4 & 0.3 & 0.4 \\
\hline 3.4 & 0.7 & 0.8 \\
\hline 6.4 & 1.3 & 1.3 \\
\hline 11.5 & 2.3 & 1.6 \\
\hline
\end{tabular}




\section{Biointrusion}

Statistical analyses of data from the short-term, small-scale biointrusion studies conducted in lysimeters (Hakonson et al. 1981) revealed that a trench cap design consisting of 60-cm of topsoil over $25-\mathrm{cm}$ of gravel $(2-\mathrm{cm}$ diameter) over a $75-\mathrm{cm}$ layer of cobble (7.5- to $13-\mathrm{cm}$ diameter) effectively limited both plant root and burrowing animal intrusion into a simulated waste emplaced beneath the cap. Although the results from this initial screening experiment were encouraging, a number of additional questions remained concerning the long-term performance of a soil/rock intiusion barrier cap design. Those questions were:

- How does the soil/rock cap design affect water balance, particularly percolation?

- How does the soil/rock cap design perform at larger scale?

- How does the soil/rock cap design perform over extended time?

- How much subsidence can be permitted and still maintain the effectiveness of the soil/rock intrusion barrier design?

The design and construction of the plot to address the question of intrusion barrier performance under various degrees of subsidence is described in detail in a previous section.

Evaluating the effecliveness of the soil/rock intrusion barrer design under various degrees of subsidence was accomplished through the use of a tracer emplaced at the interface of the trench cap and underlying backfill. A total of $73 \mathrm{~kg}$ of $\mathrm{CsCl}$ was spread uniformly, in a thin layer, on the crushed tuff backfill before placement of the soil/rock trench cap. Because cesium is plantavailable, time series analysis of the cesium content of vegetation samples can be used to indicate root penetration through the trench cap.

Although the entire plot area was seeded with a mixture of native grasses, the only plant that was successfully established on the plot was a common invader (or weed) of the genus Euforbia. Plan' cover duing the height of the growing season in 1983 was about $50 \%$. The lack of success in establishing native grass cover stems from our decision not to supplement precipitation by irrigating the plot.

Vegetation sampling on each of the plots was begun in July 1983. Samples were oven dried and submitted for neutron activation analysis to determine cesium content. Cesium concentrations in excess of $1 \mathrm{ppm}$ (background levels in plants are $<1 \mathrm{ppm}$ ) were considered indicative of root penetration to the cesium layer.

\section{Results and Discussion}

Fol reasons discussed previously, the surface subsidence craters never materialized upon opening of the covers over the subsurface void spaces. Curisequently, none of the cesium concentrations that were measured in plants are indicative of the effects of subsidence on barrier integrity. However, those data do indicate short-term performance of the soil/rock cap design at intermediate scale.

Cesium concentrations in vegetation, averaged over the entire subsidence plot area, are presented in Table XXII. Note that the concentrations all averaged less than $1 \mathrm{ppm}$, indicating that the soil/rock cap design effectively limited root access to the cesium. 


\section{TABLE XXII}

\section{AVERAGE CESIUM CONCENTRATIONS IN \\ VEGETATION FROM THE \\ SUBSIDENCE EXPERIMENT DURING \\ THE 1983 GROWING SEASON}

Date

July 11,1983

August 15, :983

Septembei 13, 1983

Gctober 4, 1983

November 8, 1983
Cesium Concentration

$(\mathrm{ppm}, \mathrm{n}=\mathbf{8})$

\begin{tabular}{ccc} 
Mean $^{\text {a }}$ & & S.D. \\
\cline { 1 - 1 } 0.14 & & 0.26 \\
0.91 & & 0.53 \\
0.08 & & 0.07 \\
0.50 & & 0.31 \\
0.50 & & 0.60
\end{tabular}

${ }^{a}$ Cesium concentrations are averaged over the entire plot area because of a lack of subsidence treatment effects.

\section{ACKNOWLEDGMENTS}

Thanks are due to C. Lujan and G. Langhorst for computer graphics and to J. Steger and J. Nyhan for guidance.

\section{REFERENCES}

Abeele, W. V., "Determination of Hydraulic Conductivity in Crushed Bandelier Tuff," Los Alamos Scientific Laboratory report LA-8147-MS (November 1979).

Abeele, W. V., M. L. Wheeler, and B. W. Burton, "Geohydrology of Bandelier Tuff," Los Alamos National Laboratory report LA-8962-MS (October 1981).

A.beele, W. V., "Geotechnical Aspects of Hackroy Sandy Loam and Crushed Tuff," Los Alamos National Laboratory report LA-9916-MS (April 1984).

Abrahams, J. H., Jr., "Physical Properties of and Movement of Water in the Bandeiier Tuff, Los Alamos and Santa Fe Counties N.M.," US Dept. of the Interior Geological Survey, tlbuquerque, New Mexico (January 1963).

Abrahams, J. H., Jr., J. E. Weir, Jr., and W. D. Purtymun, "Distribution of Moisture ir Soil and Near-Surface Tuff on the Pajarito Plateau, Los Alamos County, N.M.," US Geological Survey Professional Paper 424D, Geological Research (1961).

Baver, L. D., W. H. Gardner, and W. R. Gardner, Soil Physics (John Wiley \& Sons, Inc., New York, 1972).

Brauner, Gerhard, "Subsidence Due to Underground Mining," US Department of the Interior, Denver Mining Research Center Information Circular 8571 (1973). 
Daniel, D. E., and R. E. Olson, "Geotechnical Aspects in Design of Disposal Sites for Low-Level Radioactive Wastes," Texas Section Meeting, American Society of Civil Engineers, San Antonio, Texas (April 24, 1980).

D'Appolonia, D. J., R. V. Whitman, and E. D'Appolonia, "Sand Compaction with Vibratory Rollers," in ASCE Specialty Conference on Placement and Improvement of Soil to Support Structures (American Society of Civil Engineers, 1968).

Dunn, Irving S., L. R. Anderson, and F. W. Kiefer, Fundamentals of Geotechnical Analysis (John Wiley \& Sons, Inc., New York, 1980).

Folk, Robert, "The Distinction Beîween Grain Size and Mineral Composition in SedimentaryRock Nomenclature," Journal of Geology 62, 344-359 (1954).

General Institute of Mining Surveying. "The Movements of the Rock Masses and of the Surface in the Main Coalfields of the Soviet Union," Ugletekhizdat, Moscow (1958).

Grant, R., J. T. Christian, and E. H. Vanmarcke, "Differential Settlement of Buildings," Jou ..ul of the Geotechnical Engineering Division 100, 973-991 (September 1074).

Hakonson, T. E., G. C. White, E. S. Gladney, and M. Muller, "Preliminary Assessment of Geologic Materials to Minimize Biological Intrusion of Low-Level Waste Trench Covers and Plans for the Future," Oak Ridge National Laboratory report ORNL/NFW 81/34 (December 1981).

Head, K. H., Munual of Soil Laboratory Testing (John Wiley \& Sons, Inc., New York, 1982).

Holtz, R. D., and W. D. Kovacs, An Introduction 10 Geotechnical Engineering (Prentice-Hall, Englewood Cliffs, New Jersey, 1981).

Jumikis, Alfred, Soil Mechanics (D. Van Nostrand Co, Inc., Princeton, New Jersey, 1968).

Kahle, R., and J. Rowlands, "Evaluation of Trench Subsidence and Stabilization at Grieffield LowLevel Radioactive Waste Disposal Facility," Nuclear Regulatory Commission repori NUREG/CR-2101 (May 1981).

Lambe, T. W., and R. V. Whitman, Soil Mechanics (John Wiley \& Sons, Inc., New York, 1979).

Lutton, R. J., G. L. Regan, and L. W. Jones, "Design and Construction of Covers for Solid Waste Landfills," US Environmental Protection Agency report EPA-600/2-79-165 (1979).

National Coal Board, Mining Department, Subsidence Engineers' Handbook (National Coal Board, London. 1975).

Peck, R. B., W. E. Hanson, and T. H. Thornburn, Foundation Engineering, 2nd Edition (John Wiley \& Sons, Inc., New York, 1974).

Phillips, S. J., J. A. Winterhalder, and T. W. Gilbert "Low Level Waste Disposal Site Geotechnical Subsidence Corrective Measures: Technical Progress," in Proceedings of the Fifth Annual Participants' Information Meeting, DOE Low-Level Waste Management Program (1983).

Purtymun, W. D., and F. C. Koopman, "Physical Characteristics of the Tshirege Member of the Bandelier Tuff with Reference to Use as a Building and Ornamental Stone," US Geological Survey Open File Report, Albuquerque, New Mexico (1965). 
Sowers, G. F., Soil Mechanics and Foundations: Geotechrical Engineering (Macmillan Publishing Co., New York, 1979), th ed.

Tavenas, F., M. Bruce, J. P. Magnan, P. LaRochelle, and M. Roy, "Analyse critique de la théorie de consolidation unidimerssionnelie de Terzaghi," Revue Francoise de Géotechnique, No. 7, pp. 29-43 (1979).

Tavenas, F., P. Leblond, P. Jean, and S. Leroueil. "The Permeability of Natural Soft Clays. Part I: Methods of Laboratory Measurement," Canadian Geotechnical Journal 20(4), 629-644 (1983).

Tavenas, F., P. Jean, P. Leblond, and S. Leroueil, "The Permeability of Natural Soft Clays. Part II: Permeability Characteristics," Canadian Geotechnical Journal 20(4), 645-660 (1983).

Taylor, D. E., Fundamentals of Soil Mechanics (john Wiley \& Sons, Inc., New York, 1948).

Terzaghi, K., and R. B. Peck, Soil Mechanics in Engineering Practice (John Wiley \& Sons, New York, 1974).

43 